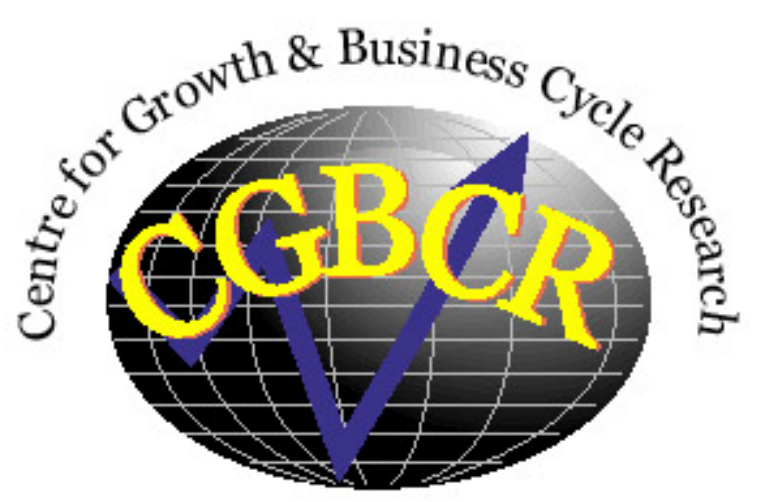

Discussion Paper Series

\title{
Identifying Changes in Mean, Seasonality, Persistence and Volatility for G7 and Euro Area Inflation
}

By

Erdenebat Bataa, Denise R. Osborn, Marianne Sensier, Dick van Dijk

Centre for Growth and Business Cycle Research, Economic Studies,

University of Manchester, Manchester, M13 9PL, UK

November 2008

Number 109

Download paper from:

http://www.socialsciences.manchester.ac.uk/cgbcr/discussionpape rs/index.html 


\title{
Identifying Changes in Mean, Seasonality, Persistence and Volatility for G7 and Euro Area Inflation
}

\author{
Erdenebat Bataa ${ }^{\dagger}$ \\ Denise R. Osborn ${ }^{\dagger}$ \\ Marianne Sensier ${ }^{\dagger}$ \\ Dick van Dijk* \\ ${ }^{\dagger}$ Centre for Growth and Business Cycles Research \\ Economics, School of Social Sciences \\ University of Manchester \\ *Econometric Institute \\ Erasmus University Rotterdam
}

\begin{abstract}
This study examines the properties of monthly CPI inflation in G7 countries and the Euro area (aggregate) over the period 1973-2007 using a new iterative decomposition procedure that separates changes in mean, seasonal and dynamic components together with conditional volatility. We uncover mean and seasonality breaks for all countries and, even allowing for these, changes in persistence are indicated for all countries except Canada. Further, while volatility reductions are widespread in the mid- to early 1980s, Canada, France and the US all exhibit increased volatility from 1999 onwards. Of methodological interest, iteration is shown to provide more evidence of persistence breaks and fewer volatility breaks overall compared with the usual approach of sequentially examining changes in the properties of inflation, while application of linear seasonal adjustment also reduces evidence of persistence breaks. Although failure to allow for breaks in mean, seasonal or dynamic components affects conclusions about the existence and dates of volatility breaks, nevertheless, evidence remains of a volatility increase in some countries in 1999.
\end{abstract}

Keywords: CPI inflation, multiple breaks, inflation persistence, seasonality, volatility JEL Classifications: E31, E52, C22

Acknowledgements: The authors gratefully acknowledge financial assistance from the Bank of England for the project "International Aspects of Macroeconomic Volatility", under which this work was initiated. However, the Bank bears no responsibility for the contents of this paper. The first and second authors would also like to acknowledge financial assistance from the UK Economic and Social Research Council (ESRC), under awards PTA-026-27-1592 and RES-062-23-1351 respectively. 


\section{Introduction}

The decline in the volatility of output and many other real macroeconomic variables in the last two decades of the twentieth century has been well documented for the US and other industrialized countries, see McConnell and Perez-Quiros (2000), Sensier and van Dijk (2004) and Stock and Watson (2005), among others. The explanations put forward for this socalled "Great Moderation” include (i) "good policy” (Clarida, Galí and Gertler, 2000), in particular more pro-active monetary policy; (ii) "good (business) practice", predominantly in the form of improved inventory management (Herrera and Pesavento, 2005), and (iii) "good luck", meaning that the typical magnitude of exogenous shocks has declined since the 1970s (Ahmed, Levin and Wilson, 2004). Blanchard and Simon (2001) argue that while the causes of the decline in US output volatility are complex, this decline can be linked to changes in the properties of inflation and particularly to a decline in inflation volatility over the period 19522001

Inflation plays a key role in monetary policy, which has changed a number of times for the US and other developed economies over the postwar period. Consequently, one stream of literature (including Altimisso et al., 2006, Benati, 2008, Cecchetti and Debelle, 2006, Levin and Piger, 2006, O'Reilly and Whelan, 2005) focuses on possible structural breaks in inflation persistence associated with monetary policy changes. Nevertheless, the frequency and extent of such persistence changes remain controversial, principally because they can be confused with changes in the underlying mean level of inflation (see Marques, 2004 and Clark, 2006). Further, Paya, Duarte and Holden (2007) find that lower frequency data exhibits higher persistence. However, despite the strong relationship between output and inflation volatility uncovered by Blanchard and Simon (2001), relatively little attention has been paid to the nature of changes in inflation volatility.

Structural breaks in mean and persistence complicate testing for changes in volatility ${ }^{1}$. For example, assume that observed annualized monthly inflation behaves like a white noise series, but with a structural change in level from $4 \%$ to $1 \%$ at one-third of the sample period.

\footnotetext{
${ }^{1}$ In a similar vein, Arellano (2006) emphasises the importance of allowing for volatility breaks when testing for mean breaks in his comment on Cecchetti and Debelle (2006). Hansen (1992) provides a simulation result showing that one's ability to detect conditional mean breaks is severely undermined in the presence of volatility breaks.
} 
It is straightforward to see that ignoring this mean break leads to the spurious conclusion that inflation volatility has declined ${ }^{2}$.

This paper directly confronts the issues associated with disentangling the nature of changes in the properties of inflation by undertaking a comprehensive examination of possible (in)stability in the mean, seasonality, persistence and (conditional) volatility of consumer price inflation for the G7 countries and the Euro area. For this purpose, we design and implement an iterative procedure to identify and distinguish between breaks in each of these inflation characteristics. Although we make use of Qu and Perron's (2007) approach to testing for multiple structural breaks, to our knowledge no procedure has previously been proposed that allows iteration between components in the context of testing for breaks.

Using monthly consumer price index (CPI) inflation rates over the period 1973-2007, we find that persistence breaks are less widespread than mean breaks. However, we find stronger evidence of persistence declines than Cecchetti and Debelle (2006), with our results largely implying zero persistence for the recent period, as in Benati (2008). Further, even taking account of mean, seasonality and persistence breaks, inflation volatility breaks are detected for all countries. In addition to widespread volatility declines in the early 1980 s, we document increases in inflation volatility for Canada, France and the US around 1999, implying (in the light of Blanchard and Simon, 2001) that the "Great Moderation" may have been a temporary phenomenon. Unusually for studies of the properties of inflation, we analyse seasonally unadjusted data. This is partly because official seasonally adjusted CPI series exist only for the US and Germany. More persuasively, however, seasonal adjustment is a filtering operation, and the smoothing implied in such adjustment may reduce the magnitude of changes in the mean and persistence properties (Ghysels and Perron, 1996). We return to this issue below.

The paper proceeds by introducing the dataset in Section 2, discussing methodology in Section 3 and analysing our results in Section 4. Section 5 offers some conclusions.

\footnotetext{
${ }^{2}$ The sample mean will be (close to) $2 \%$, such that volatility during the first one-third of the sample period, when inflation fluctuates around 4\%, appears to be much larger than during the remaining part of the sample period.
} 


\section{Data}

We analyse monthly CPI for each of the G7 countries and also the Euro area from March 1973 (post Bretton-Woods) to December 2007³ . The Euro area series relates to the countries in the Euro area at each specific date, so that Greece enters in 2001 and Slovenia in 2007. However, both countries are relatively small and hence these composition changes should not unduly affect the aggregate Euro area series. We consider monthly inflation rates, constructed as the first difference of the natural logarithm of the CPI index and multiplied by 100 .

The series analysed are shown in the upper left-hand panel in each of Figures 1 to 8 . A cursory glance at these graphs indicates the presence of outliers (see, for example, Canada in Figure 1), changes in mean inflation (such as for France, Figure 3) and/or volatility (apparently present for the US, Figure 8). In addition, many of the series are seasonal, with this perhaps being clearest for Germany and the UK (Figures 4 and 7, respectively). The next section outlines our methodology for disentangling these effects.

\section{Methodology}

This section describes our iterative testing approach used to identify and distinguish between breaks in mean, seasonality, persistence and (conditional) volatility of the inflation series. In addition, we account for the possible presence of aberrant observations by allowing for outliers. Section 3.1 details the iterative decomposition, with Section 3.2 then describing the sensitivity analyses we undertake in relation to this procedure. Finally, Section 3.3 outlines Qu and Perron's (2007) multiple break testing procedure, which is our main econometric tool.

\subsection{Iterative procedure for structural break and outlier detection}

We decompose the monthly inflation rate $Y_{t}$ into components for the level $(L)$, seasonality $(S)$, outliers $(O)$ and dynamics $(y)$, where only the last of these is stochastic. This differs from the usual unobserved components approach, as employed by Harvey (1989) and others, where both the levels and seasonal components are typically allowed to be stochastic. However, the presence of such stochastic components would imply that inflation has both a zero frequency

\footnotetext{
${ }^{3}$ Data for G7 countries are obtained from the OECD (www.oecd.org), and the Euro area series from Datastream. The latter series is the Euro area harmonised index of consumer prices (HICP) produced by Eurostat when this is available, but constructed by Datastream prior to 1990 .
} 
unit root and the full set of seasonal unit roots, a conclusion which has not found support in previous analyses of inflation; see, for example, Canova and Hansen (1995) for the US and Osborn and Sensier (2008) for the UK.

Therefore, allowing for structural change in each of the components, we consider the model

$$
\begin{array}{lrl}
Y_{t}=L_{t}+S_{t}+O_{t}+y_{t} & \\
L_{t}=\mu_{j} & t=T_{k_{1}-1}+1, \ldots, T_{k_{1}} ; \quad k_{1}=1, \ldots, m_{1}+1 \\
S_{t}=\sum_{l=1}^{s} \delta_{k_{2} l} D_{l t} & t=T_{k_{2}-1}+1, \ldots, T_{k_{2}} ; \quad k_{2}=1, \ldots, m_{2}+1 \\
y_{t}=\sum_{i=1}^{p} \phi_{k_{3}, i} y_{t-i}+u_{t} & t=T_{k_{3}-1}+1, \ldots, T_{k_{3}} ; \quad k_{3}=1, \ldots, m_{3}+1 \\
\operatorname{var}\left(u_{t}\right)=\sigma_{k_{4}}^{2} & t=T_{k_{4}-1}+1, \ldots, T_{k_{4}} ; \quad k_{4}=1, \ldots, m_{4}+1
\end{array}
$$

where $t_{0}=0 ; T_{m+1}=T$ ( $T$ denotes the total sample size $)$ and for $s$ seasons per year $(s=12$ for monthly data), $D_{l t}, l=1, \ldots, s$ are seasonal dummies equal to unity if the observation at time $t$ falls in season $l$ and zero otherwise. Note that the coefficient $\delta_{k, l}$ represents the deviation of the unconditional mean of inflation in the $l$-th season (month) from the overall mean level $\mu_{j}$ and, for identification purposes, we impose the restriction $\sum_{l=1}^{s} \delta_{k_{2} l}=0$ for all seasonality regimes $k_{2}=1, \ldots, m_{2}+1$. Outliers, $O_{t}$, are defined as observations more than five times the interquartile range away from the "local" median, using the procedure adopted by Stock and Watson (2003). Once an outlier is detected we replace it with the median of the six neighbouring non-outlier observations ${ }^{4}$. The specification of (2)-(5) allows $m_{1}$ breaks in the level component $L_{t}, m_{2}$ breaks in the seasonal component $S_{t}, m_{3}$ breaks in the autoregressive coefficients of the dynamic component $y_{t}$ and $m_{4}$ breaks in conditional volatility. It is important to note that the number of structural breaks in these four components do not have to be the same and nor do their temporal locations.

It is difficult, if not impossible, to test satisfactorily for multiple structural breaks in all components of (1) in a simultaneous procedure if these breaks may occur at different dates.

\footnotetext{
${ }^{4}$ The procedure is available on Mark Watson's website http://www.princeton.edu/ mwatson/publi.html, in the replication files for Stock and Watson (2003). Our application uses a "local" median, in the sense that their procedure is applied within the iterations through which levels shifts and seasonals are removed. Neighbouring observations are also considered in this context.
} 
Complications arise because the structural break testing methodologies developed so far assume a pre-specified distance between consecutive break dates, thus limiting the possible number of breaks. For example, using 15\% trimming in the methodology of Bai and Perron (1998, 2003) or Qu and Perron (2007) would allow at most 5 breaks in the parameters in any of (2) to (5) over the 35-year sample period we analyse. However, potential changes in seasonal patterns due to (say) changes in data collection methods or to tax effects, considered alongside mean and/or persistence shifts arising from changes in monetary policy and volatility changes due to good luck renders plausible the existence of more than a total of five parameter changes over our sample. Nevertheless, estimating and testing for breaks sequentially also poses problems, since testing for structural breaks in one component can be affected by the presence of breaks in other components. For example, Marques (2004) shows empirically that conclusions concerning changes in inflation persistence crucially depend on the specification of mean inflation, with much more evidence for a decline in inflation persistence obtained if mean inflation is assumed constant than if the level is allowed to exhibit structural breaks. Similarly, reconsider the example in the Introduction where a series exhibits a large structural break in mean at one-third of the sample period. If this series has stable deterministic seasonality, ignoring the level shift will spuriously suggest that a break in the seasonal pattern has occurred. In addition to these, a further complication is that the presence of outliers can affect persistence estimates; see Franses and Haldrup (1994).

Therefore, we employ an iterative approach to examine breaks in each of the components of the inflation series alongside outlier detection and removal. First, the level, seasonal and dynamic parts are each set to zero in order to initialise the process, with outliers then detected ${ }^{5}$. Second, having corrected for outliers, and with the dynamics still set to zero, we test for breaks in the seasonal component ${ }^{6}$ and obtain (using the appropriate sub-samples) our first estimate of the seasonal part that allows for structural instability. Third, we subtract the seasonal component from the original series and test for level shifts. The break dates are recorded, leading to the first estimate of mean inflation, adjusted for any breaks uncovered. In the fourth step of the loop, having removed outliers, seasonal and level components from the

\footnotetext{
${ }^{5}$ Outliers are corrected so as to impose minimal distortion. For example, a permanent level shift in CPI, perhaps caused by an introduction of consumption tax that leads to a single outlier in inflation, is adjusted in the inflation series. However, if a single event leads to an abnormal increase in the CPI series that returns to close to its previous level in the following month, we make a single outlier correction in the CPI series, rather than making two corrections in the inflation data. Outlier correction is sequential, correcting the first outlier and then checking for any remaining outliers, with additional outliers then removed until no more are detected.

${ }^{6}$ Alternatively, initial mean breaks could be considered prior to initial seasonal breaks. However, the only impact of considering mean breaks first is a relatively marginal change in the date of one mean break for Germany.
} 
original series, we test for breaks in the autoregressive (AR) coefficients of the dynamic component.

This loop is iterated until convergence is achieved for the dates of outliers and structural breaks ${ }^{7}$. In these iterations, the latest estimates of all components are removed, except for that under study. Thus, for example, level, seasonal and dynamic (AR) components are removed when outliers are examined, while the latest detected outliers, mean and dynamics are removed when testing for seasonal breaks. This analysis is conducted using heteroskedasticity robust inference throughout.

Once convergence is achieved in the iterative procedure just described for the components of (1), we could in principle subtract these four components from the original series and proceed with testing for (conditional) volatility breaks in the residuals $\hat{u}_{t}$. However, Pitarakis (2004, page 44) notes that "It is a notoriously difficult problem to design good test procedures about the equality of regression slopes while not necessarily maintaining the equality of variance assumption". Indeed, Hansen (2000) shows that structural changes in the marginal distribution of regressors render the Andrews (1993) type structural break tests asymptotically invalid. This situation may be relevant for our analysis given the empirical evidence for structural breaks in volatility of inflation, see Blanchard and Simon (2001), Sensier and van Dijk (2004), and Stock and Watson (2007), among others.

To account for this possibility we incorporate an additional 'inner loop' that iterates between testing for breaks in the AR coefficients of the dynamic component $y_{t}$ and its conditional volatility. To be precise, after removing outliers, mean and seasonal components, the sub-loop tests for breaks in dynamics; in the first iteration this employs heteroscedasticity robust inference, but subsequently a constant variance assumption is used ${ }^{8}$. If any break is detected, the AR model is estimated allowing for these breaks, with variance breaks then investigated using the resulting residuals. If volatility breaks are detected, the residual variances are estimated over the implied volatility segments. Weighting the $y_{t}$ series with the estimated standard deviations, the test for breaks in dynamics is again applied, and so on until convergence is achieved in the dynamics/volatility break dates. Once this 'inner loop' has converged, we return to the main loop and proceed as above.

\footnotetext{
${ }^{7}$ Since we lose $p$ observations in order to estimate the $\operatorname{AR}(p)$ model, and consequently our dynamic component will be $p$ observations short of others, we set missing dynamic components to their unconditional mean of zero.

${ }^{8}$ Pitarakis (2004) uses Monte Carlo simulations to assess the properties of mean break tests in the presence of volatility break, uncovering an extreme size distortion that actually increases with the sample size. He then provides evidence on improvements offered by a GLS transformation in that context.
} 
In the implementation of this procedure, the maximum number of iterations is set to 20. In a small number of cases, the procedure does not yield converge to a unique set of break dates, but rather converges to a cycle between two sets of dates. In such cases, we select between these sets based on the minimization of the Hannan-Quinn (HQ) information criterion, defined in this context as

$$
\begin{aligned}
H Q=\sum_{k_{4}=1}^{m_{4}+1} \ln \left(\sum_{t=T_{k^{-1}-1}+1}^{T_{k_{4}}} \hat{u}_{t}^{2} /\left(T_{k_{4}}-T_{k_{4}-1}\right)\right)+ \\
\quad \frac{2 \ln (\ln (T))}{T}\left[m_{1}+1+12\left(m_{2}+1\right)+p\left(m_{3}+1\right)+m_{4}+1\right] .
\end{aligned}
$$

\subsection{Sensitivity analyses}

The iterative procedure outlined above models seasonality as deterministic, both for the statistical reason that there is little evidence that CPI series contain stochastic seasonal unit roots and also because seasonality in prices partly reflects institutional effects (such as the timing of indirect tax changes) and the construction methodology, with these effects better represented as changing at specific dates rather than continuously changing. In this respect, one notable change in seasonality in CPI occurs during the 1990s or early 2000s, when price reductions due to 'sales' are first included in the calculation of consumer prices for a number of Euro area countries, including France and Germany (Commission of the European Communities, 2000, p.66; Bilke, 2005). Also, Hamid and Dhakar (2008) present evidence that seasonality in monthly CPI inflation for the US differs between republican and democratic presidencies.

However, it is more common to study changes in the properties of CPI inflation after the application of a seasonal adjustment filter. Therefore, we present summary results for the case where the linear X-11 filter coefficients are used to capture seasonal effects, in place of the deterministic seasonal model of (3). The X-11 filter coefficients are embedded within the iterations, rather than being applied prior to other analysis, in order to replicate some of the sophistication of the X-12-ARIMA seasonal adjustment methodology in terms of outlier detection and dynamics (see, for example, Ghysels and Osborn, 2001, pp.106-108).

Another set of summary results presented investigates the results of taking a single pass through the outlier, seasonality, levels, dynamics and volatility breaks procedure outlined in the preceding subsection. Comparison with the principal results therefore allows the effects of iteration to be seen. Finally, we present results obtained when the seasonal, level and 
dynamic components of (1) are assumed constant over the sample period, with only outliers and volatility breaks taken into account. These last results focus on the sensitivity of the volatility breaks to the assumptions made about other components, and are obtained both without and with iteration between outliers and volatility.

\subsection{Testing for multiple structural breaks}

The iterative procedure of the previous subsection is implemented using the $\mathrm{Qu}$ and Perron (2007) test for multiple structural breaks ${ }^{9}$. At each step, following the recommendation of Bai and Perron (2006), we first test the null hypothesis of no breaks against an unknown number of breaks. If the null of no breaks is rejected we use a sequential testing procedure to estimate the number and locations of breaks.

All tests relating to the components of (1) are examined in a regression framework, with the form of the regression varying according to the component being tested for structural breaks. Specifically:

(i) To test for breaks in the seasonal component $S_{t}$, we regress $Y_{t}-\hat{L}_{t}-\hat{O}_{t}-\hat{y}_{t}$ on a set of centred seasonal dummies $\Delta_{j t}=D_{j t}-D_{k t}, j=1, \ldots, s-1$ (where $D_{j t}$ is a conventional zero/one seasonal dummy variable for season $j$ ) that is $Y_{t}-\hat{L}_{t}-\hat{O}_{t}-\hat{y}_{t}=\sum_{\substack{j=1 \\ j \neq k}}^{s} \delta_{i j} \Delta_{j t}+u_{t}$, with the omitted season $k$ coefficient retrieved as $\delta_{i k}=-\sum_{\substack{j=1 \\ j \neq k}}^{s} \delta_{i_{j}}$. The estimated AR coefficients for the dynamic component $y_{t}$ are used to form $\hat{y}_{t}$.

(ii) For the level component $L_{t}$, we employ the regression $Y_{t}-\hat{S}_{t}-\hat{O}_{t}-\hat{y}_{t}=\mu_{i}+u_{t}$.

(iii) To test for breaks in the dynamic component $y_{t} \equiv Y_{t}-\hat{L}_{t}-\hat{S}_{t}-\hat{O}_{t}$, use an $\operatorname{AR}(p)$ model $\phi_{i}(L) y_{t}=u_{t}$, with AR polynomial $\phi_{i}(L)=1-\phi_{i 1} L-\phi_{i 2} L^{2}-\ldots-\phi_{i p} L^{p}$ in the lag operator $L$.

\footnotetext{
${ }^{9}$ Although the Qu and Perron (2007) procedure is developed for multivariate systems, it is adopted here because of its attractive features, including the possibility of using volatility break information when testing for mean breaks, as well as an explicit handling of volatility breaks that allows us to avoid the current practice of using mean break tests in conjunction with some form of volatility proxy in the context of the Bai and Perron (1998, 2003) methodology. Further, our Monte Carlo experiments indicate increased precision of volatility break dating using Qu and Perron's (2007) maximum likelihood estimator.
} 
In all cases, the most recent estimates are employed when constructing the dependent variable for the regression.

To test the null hypothesis $H_{0}: \mu_{i}=\mu_{0} \quad\left(i=1, \ldots, m_{1}+1\right), H_{0}: \boldsymbol{\delta}_{i}=\boldsymbol{\delta}_{0}$ $\left(i=1, \ldots, m_{2}+1\right)$ where $\boldsymbol{\delta}_{i}=\left(\delta_{i 1}, \ldots, \delta_{i s}\right)^{\prime}$, or $H_{0}: \phi_{i}=\phi_{0} \quad\left(i=1, \ldots, m_{3}+1\right)$ where $\boldsymbol{\phi}_{i}=$ $\left(\phi_{i 1}, \phi_{i 2}, \ldots, \phi_{i p}\right)$ ', against $m \leq M$ breaks (for a specified maximum $M$ ) we employ the statistic

$$
W D \max =\max _{1 \leq m \leq M} a_{m}\left[\sup F_{T}(m, q, \varepsilon)\right]
$$

where $a_{1}=1$ and for $m>1, m$ is $m_{1}, m_{2}$ or $m_{3}$, as appropriate, $a_{m}=c(\alpha, 1) / c(\alpha, m)$, in which $c(\alpha, m)$ is the asymptotic critical value of the supremum statistic $\sup F_{T}(m, q, \varepsilon)$ at significance level $\alpha$, in which

$$
\sup F_{T}(m, q, \varepsilon)=\sup _{\left(\lambda_{1}, \ldots, \lambda_{m} \in \Lambda_{\ell}\right)}\left[\left(\frac{T-(m+1) q}{m}\right) \hat{\beta}^{\prime} R^{\prime}\left[R \hat{V}(\hat{\beta}) R^{\prime}\right]^{-1} R \hat{\beta}\right]
$$

is a Wald-type test statistic for structural change at $m$ unknown break dates, $\hat{\beta}$ is the vector of coefficients, that is , $\hat{\mu}, \hat{\boldsymbol{\delta}}$ or $\hat{\boldsymbol{\phi}}$, for $m$ breaks at given dates with estimated covariance matrix $V(\hat{\boldsymbol{\beta}}), \boldsymbol{R}$ is a non-stochastic matrix such that $(\boldsymbol{R} \boldsymbol{\beta})^{\prime}=\left(\boldsymbol{\beta}_{1}^{\prime}-\boldsymbol{\beta}_{2}^{\prime}, \ldots, \boldsymbol{\beta}_{\boldsymbol{m}}^{\prime}-\boldsymbol{\beta}_{\boldsymbol{m}+1}^{\prime}\right), q$ is the number coefficients (all of which are allowed to change), $\lambda_{i}(i=1, \ldots, m)$ indicate the break dates as fractions of the sample size, that is, $0<\lambda_{1}<\ldots<\lambda_{m}<1$ with $T_{i}=\left[T \lambda_{i}\right]$ and finally $\Lambda_{\varepsilon}$ denotes all permissible sample partitions. To allow for potential breaks in the residual variance for each equation, we use the Heteroskedasticity Consistent (HC) version of the tests when testing for the presence of breaks. Moreover, in the first iteration for mean and seasonal breaks we also allow for autocorrelation through the use of HAC, using the quadratic spectral kernel with automatic bandwidth selection as in Andrews (1991).

If the WDmax test of (7) rejects the null of no breaks at the 5\% significance level, a sequential $F$-type test is used to determine the number of breaks and their locations. In particular, the test statistic is defined as 


$$
\sup S E Q_{T}(l+1 \mid l)=\max _{1 \leq j \leq l+1}\left[\sup _{\tau \in \Lambda_{j, \varepsilon}} F_{T}\left(\hat{T}_{1}, \ldots, \hat{T}_{j-1}, \tau, \hat{T}_{j}, \ldots, \hat{T}_{l}\right)-F_{T}\left(\hat{T}_{1}, \ldots, \hat{T}_{l}\right)\right]
$$

where $\Lambda_{j, \varepsilon}=\left\{\tau ; \hat{T}_{j-1}+\left(\hat{T}_{j}-\hat{T}_{j-1}\right) \varepsilon \leq \tau \leq \hat{T}_{j}+\left(\hat{T}_{j}-\hat{T}_{j-1}\right) \varepsilon\right\}$ for $l=1,2, \ldots$, and $F_{T}$ is given by (8). The test statistic in (9) is applied for $l=0,1, \ldots, m$ until the test fails to reject the null hypothesis of no additional structural breaks. Note that, for each value $l$, the estimates of all break dates are re-estimated to find those corresponding to the global maximum of the likelihood function.

The null hypothesis of no break in conditional volatility, $H_{0}: \sigma_{i}^{2}=\sigma_{0}^{2}$ $\left(i=1, \ldots, m_{4}+1\right)$, is tested using a likelihood ratio test statistic. In particular, the $\operatorname{Sup} F$ statistic of (7) is replaced by the $\operatorname{Sup} L R$ statistic defined as

$$
\sup L R_{T}(m, q, \varepsilon)=\sup _{\left(\lambda_{1}, \ldots, \lambda_{m} \in \Lambda_{\ell}\right)} 2 \ln \left(\frac{\hat{L}_{T}\left(T_{1}, \ldots, T_{m}\right)}{\widetilde{L}_{T}}\right)
$$

where $\ln \hat{L}_{T}\left(T_{1}, \ldots, T_{m}\right)=-\frac{T}{2}(\ln 2 \pi+1)-\sum_{j=1}^{m+1} \frac{T_{j}-T_{j-1}}{2} \ln \hat{\sigma}_{j}^{2}$ and $\hat{\sigma}_{j}^{2}=\frac{1}{T_{j}-T_{j-1}} \sum_{t=T_{j-1}+1}^{T_{j}} \hat{u}_{t}^{2}$ with $\hat{u}_{t}(t=1, \ldots, T)$ the residual series from (4), while $\sim$ represents the corresponding quantities computed under the null hypothesis of no volatility breaks. Similarly, the sequential test of (9) is replaced by

$$
\sup S E Q_{T}(l+1 \mid l)=\max _{1 \leq j \leq l+1}\left[\sup _{\tau \in \Lambda_{j, \varepsilon}}\left(\ln \left(\frac{\hat{L}_{T}\left(T_{1}, \ldots, T_{j-1}, \tau, T_{j}, \ldots, T_{l}\right)}{\hat{L}_{T}\left(T_{1}, \ldots, T_{l}\right)}\right)\right)\right]
$$

Having obtained the number of structural breaks using (9) or (11), as appropriate, the break dates are estimated as those that maximise the corresponding statistic. Using the methodology of Qu and Perron (2007), 90\% confidence intervals are also computed for the break dates.

From a practical point of view the maximum number of breaks, $M$, needs to be specified, as well as the minimum fraction $\varepsilon$ of the sample in each regime. Critical values of 
the tests depend on both the number of coefficients allowed to change and $\varepsilon$. In general $\varepsilon$ has to be chosen large enough for tests to have approximately correct size and small enough for them to have decent power. Moreover, when the errors may be autocorrelated and/or heteroskedastic, $\varepsilon$ has to be larger than when these features are absent. In order to balance these issues, we set $\varepsilon=0.2$ and $M=2$ when the tests are applied for the seasonal component ${ }^{10}$ and $\varepsilon=0.15$ with $M=5$ otherwise.

\section{Results}

Section 4.1 discusses our principal empirical results concerning the presence of structural breaks in different characteristics of monthly CPI inflation for each of the G7 countries and the Euro area over the period March 1973 to December 2007, obtained using the iterative decomposition procedure described in Section 3.1. Section 4.2 considers the sensitivity analyses.

\subsection{Iterative decomposition results}

Figures 1 to 8 show the decomposition resulting from the application of the iterative method. From the upper left-hand chart, and moving first from left to right, the charts show: (a) the original unadjusted CPI inflation series; (b) the estimated dynamic component $y_{t}$ (constructed by removing outliers, mean and seasonal components) together with its estimated persistence, defined as the sum of the autoregressive coefficients in (4) and corresponding \pm 2 standard error bands (in red), and volatility break dates (vertical green lines); (c) the level component $L_{t}$ with \pm 2 standard error bands; (d) the estimated seasonal component for each seasonal regime (again with \pm 2 standard error bands); (e) outliers $O_{t}$ that are removed; and (f) the correlogram of the dynamic component $y_{t}$ within each dynamic regime $j$, together with an approximate $95 \%$ confidence interval of $\pm 2 \sqrt{1 /\left(T_{j}-T_{j-1}\right)}$. With the exception of the correlogram, all standard errors are obtained using the White (1980) HC covariance matrix in the corresponding regression. Where relevant, the graphs showing the seasonal components

\footnotetext{
${ }^{10}$ Of course, only one observation per year is available on monthly seasonal effects, implying that relatively few structural changes can be realistically allowed in these. The fraction $\varepsilon=0.2$ is specified to allow for the inclusion of 'sales' prices in CPI in a number of Euro area countries in the 1990s/early 2000s (Commission of the European Communities, 2000, p.66). The use of $\varepsilon=0.3$ results in seasonal breaks for a number of countries estimated at the end-point of the interval allowed, while $\varepsilon=0.2$ yields more satisfactory results overall.
} 
and the correlograms for the dynamic component are colour-coded with the first regime (that is, the sub-sample to the first break date) in blue, the second in red and the third in pink.

Table 1 provides numerical results, which supplement the graphical ones presented in the figures. Several interesting conclusions emerge. Firstly, consider the mean breaks results reported in Panels A and B. All eight countries (where, for simplicity we refer to the Euro area as a 'country') experience at least one mean break in the first half of the 1980s, with inflation falling by more than half by the end of 1985 compared to its value at the beginning of the sample (compare the regime means in Panel B). The high inflation levels of the 1970s, of course, reflect the global price shocks of large oil price increases. Further, Canada, Euro area France, Italy and the UK all experience further declines in the early 1990s, with all countries then having inflation rates between $0.15 \%$ and $0.25 \%$ a month. In the case of Japan, however, mean inflation from late 1998 is negative, reflecting the long-lasting deflationary episode it has experienced. These patterns of declines in underlying inflation levels are also evident as the downward 'steps' in the mean graphs of Figures 1 to 8.

For some countries mean breaks are dated just before the introduction of inflation targeting, with November 1990 for Canada (target adopted in February 1991) and March 1992 for the UK (inflation target announced in October 1992). In both cases the inflation target adoption dates lie within the $90 \%$ confidence intervals for the break dates, which are also shown in Table 1. Altissimo et al. (2006) point out that 1990s breaks for countries that adopted the euro (and, by implication, for the Euro area aggregate) may correspond to implementation of the nominal convergence required by the Maastricht Treaty, which was signed in February $1992^{11}$. Overall, and in line with Cecchetti and Debelle (2006), Altissimo et al. (2006) and others, it is evident that level shifts since the early 1970s are an important feature of the inflation process for these countries.

Secondly, Panels C and D in Table 1 indicate that all countries two experience breaks in their seasonal patterns, with these patterns altering in both the 1980 and 1990s in Canada, Italy, Japan and UK, with changes in the 1990s and around 2000 for the Euro area, France, Germany and the US. Indeed, the close co-incidence of the dates for changed seasonality in the Euro area, France and Germany is notable. As anticipated, due to the change in the prices covered, the magnitude of seasonality increases from 2000 for the Euro area, with such an increase taking place in 1992 for France, due to their inclusion of sales prices from this date.

\footnotetext{
${ }^{11}$ Although Germany does not experience any 1990s mean break, those for other Euro area countries may be viewed as bringing their inflation levels into line with those already experienced by Germany.
} 
Bilke (2005) notes that the inclusion of such prices for France was completed in 1998, which corresponds to the second seasonal break date we detect for this country in Panel C. The marked seasonal effect for the UK in April is due to the traditional timing of the implementation of indirect tax changes arising from the annual government budget; see Figure 7, Seasonal chart. The change in seasonality in 1993 in Panel C is close to that found by Osborn and Sensier (2008) for the UK retail price index and may be due to the timing of budgets being disrupted from that year ${ }^{12}$.

As evident from the seasonal components graphed in Figures 1 to 8 , these large northern hemisphere countries typically see lower than average inflation during the summer months, although this is less marked in the US than in other countries. With the exception of Japan, strong negative seasonal effects are seen in December or January, although the timing of this sometimes changes (for example, in France). The inclusion of price reductions during sales has a clear impact on the changed seasonal patterns in these months for Germany and the Euro area from 2000.

Thirdly, outliers are reported in Panel E of Table 1. Some of these are related to tax changes, such as the introduction of the Canadian Goods and Services Tax in January 1991 or the introduction of the UK Council Tax in April 1991.

Fourthly, Panel F shows the AR lag lengths for the dynamic component chosen using the HQ criterion employed when testing dynamic breaks in the final iteration ${ }^{13}$. When HQ selects a zero lag length, then a lag of 1 is adopted for inference purposes.

Finally, Panel G shows the number of iterations required to achieve convergence. These range from 4 to 19 , illustrating the interactions between the structural breaks in the components of the model in (1). For Germany and the UK, the iterative procedure cycles between two sets of break dates, with results presented being those which minimize the HQ criterion of (6), with values shown in Panel $\mathrm{H}$ of Table 1 . However, in each case the two cycles are very close to each other, with no substantive difference between their implications ${ }^{14}$.

Turning to Table 2, it is notable that inflation dynamics remain unchanged from 1973 only for Canada (Panel A), which effectively has zero inflation persistence (Panel B). Whereas studies that examine inflation persistence allowing for mean breaks (including

\footnotetext{
${ }^{12}$ The dates for all UK budgets since 1900 can be found at http://www.hm-treasury.gov.uk/5511.htm.

${ }^{13}$ The maximum number of lags considered is $\operatorname{Pmax}=$ integer $\left(12 *(T / 100)^{1 / 4}\right)$.

${ }^{14}$ Compared with the results in Table 1, the other set of break dates differ in relation to the first seasonal break for both countries, with that for the UK being in February 1982 and for Germany in October 1991.
} 
Cecchetti and Debelle, 2006, and Levin and Piger, 2006) typically assume unchanged inflation dynamics, our procedure uncovers one break in the AR coefficients for all countries except Canada. Indeed, inflation persistence, measured in Panel B as the sum of the AR coefficients, is always very low after the dynamic break. This is true even though persistence is typically around 0.4 or more when computed over the whole sample period with mean breaks, but not dynamic breaks, taken into consideration (shown in parentheses in Panel B).

Two other aspects of our results in relation to persistence should be noted. Firstly, as indicated in Panel C, the HQ criterion selects zero lags in the second dynamic regime for all countries except Italy and the US, emphasising that estimated persistence (obtained from the use of an AR(1) model) is effectively zero for such countries. For the US, the aggregate of the two estimated AR coefficients is almost exactly zero, and hence only Italy is estimated to have substantial inflation persistence at the end of the sample. The second piece of evidence is provided by the correlograms for the dynamic component (that is, $Y_{t}-\hat{L}_{t}-\hat{S}_{t}-\hat{O}_{t}$ ), shown in the bottom right-hand panel of each of Figures 1 to 8 , where almost all autocorrelations are typically within the confidence bands around zero either over the whole sample period (Canada) or in the final dynamic regime (Euro area, France, Germany, Japan and UK). Therefore, although Panel A indicates that the timing of the persistence change differs across countries, our result that it has been eliminated is stronger than evidence found by others that taking into account mean breaks generally lowers persistence estimates (see, for instance, Altimisso et al., 2006, Cecchetti and Debelle, 2006, Levin and Piger, 2006). However, our results in Table 2 and Figures 1 to 8 are largely in accord with the conclusion of Benati (2008) that recent inflation in countries such as Canada, the US and the Euro area can be treated as effectively a white noise process.

Having taken into account the effects of multiple structural breaks in level, seasonal and dynamic components as well as outliers through the model given by (1) to (4), Panels D and $\mathrm{E}$ of Table 2 provide evidence on changes in (conditional) inflation volatility. The results in Panel D are broadly consistent across countries, with most countries experiencing a volatility break in the first half of the 1980 s, corresponding to the beginning of the Great Moderation. However, there is also evidence of this moderation coming to an end around the close of the century, with volatility increases dated during 1999 for Canada, France and the US. Particularly noteworthy is the US, for which we find that (conditional) inflation volatility more than doubles from 0.09 to 0.20 . Japan shows a different pattern, with an early volatility 
decline (in 1979), followed by a further decline in 1999. This latter result is in accord with the visual impression from Figure 6 of low and steady inflation in Japan.

The correlograms of the estimated dynamic component in Figures 1 to 8 also imply that the relatively simple model of (1) to (4) adequately captures the seasonal pattern in the series, since there is little evidence of significant positive serial correlation at a lag of 12 months. The only exceptions are the UK, where there is modest evidence of such serial correlation in the second dynamic regime (after 1990) and for the US, where there are a number of significant positive and negative autocorrelations around the annual lag. However, in the latter case the second dynamic regime is dated from 1999, and the relatively small number of observations in this regime implies that inference may be unreliable. Further, as noted in the next subsection, these autocorrelation patterns for the US in this period are not specific to the use of the model given by (1) to (4).

\subsection{Sensitivity analysis}

Table 3 provides summary results relating to four different model choices. Firstly, in Panel A, the monthly linear X-11 filter ${ }^{15}$ replaces the deterministic seasonal model of (3) within the iterations, while in Panel B the model of (1) to (4) is employed without iteration (that is, outliers are removed, with seasonality breaks, mean breaks, dynamic breaks and volatility breaks then estimated in that order). Finally, Panels C and D show the results when only outliers are removed before volatility breaks are estimated, without and with iteration respectively.

Comparing the mean breaks in Panels A and B of Table 3 with those of Table 1, it is clear that estimated mean breaks are relatively invariant to the treatment of seasonality or to making a single pass through the algorithm. Indeed, only for France is the number of mean breaks sensitive to the choice made. Also, the use of the X-11 seasonal filter generally leads to very similar outliers to those in Table 1 and hence, to conserve space, the dates of these are not recorded in Table 3. However, the smoothing behaviour of the filter can conflate outliers, seasonality and mean breaks, and hence may lead to spurious volatility breaks. It is particularly notable that the X-11 linear filter hides the reunification outliers detected for

\footnotetext{
${ }^{15}$ Seasonal adjustment is applied using the procedure of Stock and Watson (2003), which avoids end-point problems by using AR models to forecast and backcast observations required to employ the two-sided symmetric filter.
} 
Germany in Table 1 (Panel E), with these instead being associated with an apparent volatility change during 1993 in Panel A of Table 3.

However, seasonal adjustment sometimes has a substantial influence on estimated dynamic breaks and on volatility breaks. More specifically, no dynamic breaks are found for Germany or Japan in Panel A of Table 3, which is presumably due to the smoothing inherent in the filter (Ghysels and Perron, 1996), while the dates of detected breaks differ markedly from those of Table 2 for Italy and the US. Further, adjustment leads to the seasonal break detected in Table 2 for the Euro area in 2000 (and attributed to the inclusion of sales prices in CPI) being associated with a volatility break in Panel A of Table 3. It is also notable that the volatility breaks in the early 1980s for each of France, Germany and Italy found after seasonal adjustment are (surprisingly) not uncovered when the corresponding Euro area aggregate is examined.

Although correlograms of the dynamic component after adjustment using the $\mathrm{X}-11$ filters are not shown, such adjustment leaves significant serial correlation for all series at seasonal lags. This is presumably because the implicit assumptions made about the properties of the series when this filter is applied are not satisfied for these monthly inflation series.

As noted above, official seasonally adjusted CPI data are available only for Germany and the US. When the iterative procedure of Subsection 3.1 is applied to these data, skipping the seasonal modelling stage, this yields one mean break for Germany, early in the $1980 \mathrm{~s}$, but no dynamic breaks and five volatility breaks. These results for Germany are very similar to those reported in Panel B of Table 3 and discussed below. For the US, however, the results largely reproduce those in Panel A, except that the dynamics and volatility breaks in 1984 and 1983 (respectively) are absent. Two other features of the official seasonally adjusted series are notable in relation to the US results in Tables 1 and 2. Firstly, this data does not imply that persistence declines to zero in the second dynamic regime. Secondly, the correlogram for the dynamic component in this second regime is very similar to that shown in Figure 8, so that the positive and negative significant autocorrelation around the annual lag in the latter part of the sample period is not a consequence of the assumptions about seasonality embedded in the deterministic specification of (3).

In comparison with the seasonal breaks in Table 1, obtained after iterating, those in Panel B of Table 3 are fewer in number; for example, the breaks for France associated in the previous subsection with changed treatment of sales prices are not found in this latter table. Nevertheless, the seasonality breaks for Germany, Japan and the UK are largely unchanged. 
Overall, however, the greatest impact from iteration comes in the dynamic and volatility break analysis, which backs up the simulation findings of Hansen (1992) and Pitakaris (2004). The apparent difficulty in detecting persistence breaks in the presence of ignored volatility breaks is evident from the disappearance of persistence breaks in Germany, Italy, Japan and the UK, which would lead (from Panel B of Table 3) to the conclusion that the dynamics of inflation in these countries has been unchanged since 1973. This implies that the application of a sequential methodology in previous analyses (including Cecchetti and Debelle, 2006) could explain their failure to detect persistence breaks after mean breaks are taken into account. Further, the volatility break results in Panel B of Table 3 suggest that undetected persistence breaks leads to over-specification of volatility breaks.

In general, iteration between breaks in the components of (1) to (4) helps to uncover important interreactions among them. Indeed, it is quite common that outliers are hidden by structural changes in other components, especially the mean. For example, outliers in Canada, Germany and Italy are undetected in Panel B of Table 3, due to the failure to recognise mean breaks, despite the visual evidence for these outliers in Figures 1, 4 and 5 respectively. One impact of these neglected outliers is spurious volatility breaks, a phenomenon discussed by van Dijk, Franses and Lucas (1999). Another consequence of a single pass is the disappearance of seasonality breaks for Canada, France and Italy, which can affect evidence of volatility breaks.

When no breaks are considered in the systematic part of the model, namely no breaks are permitted in (2), (3) or (4), then (as may be anticipated) relatively more evidence is found for volatility breaks. For Canada, the Euro area, Germany and the US more volatility breaks are identified in Panel C of Table 3 than in Table 2, but fewer are found for Italy and Japan. However, iteration between outlier and volatility breaks in Panel D apparently improves discrimination between these. This is most clear for Canada, where the detection of one outlier after iteration in Panel D reduces the number of volatility breaks from five to two. On the other hand, iteration increases both the number of outliers and the number of volatility breaks for Italy, while both are reduced for the UK.

Thus, interaction between outliers and volatility breaks can be very important. Even in this simple set-up where other components are assumed to be constant, this illustrates the importance of handling outliers within a model, rather than correcting them at a prior stage, as is common in empirical studies. 
Nevertheless, the increase in the volatility of Canadian and US inflation around 1999 is not sensitive to the specific methodology employed. Although sometimes dated in 2000 or 2001 , this volatility break is significant for both countries in Panel D of Table 2, and in each of Panels A, B and C of Table 3. This break is also detected when official US seasonally adjusted data are employed. However, the volatility break for France around the same date in Table 2 is not always present in Table 3.

\section{Conclusions}

This paper proposes an iterative procedure for the decomposition of a time series into level, seasonality, outlier and dynamic components, together with conditional volatility, when these components are permitted to exhibit distinct multiple structural breaks over the sample period. To our knowledge, such a procedure has not been proposed previously, with analyses that allow distinct breaks (such as mean and volatility in Sensier and van Dijk, 2004) considering these sequentially. However, our results suggest that substantially more evidence of change can be uncovered when the iterative procedure is used rather than a sequential procedure, with outliers also being identified more adequately. Further, compared with seasonally adjusting the data, we believe that this iterative procedure based on deterministic mean and seasonal effects allows a clearer distinction to be drawn between the various characteristics of inflation and the dates at which these characteristics have changed.

Application of the new procedure to monthly CPI inflation in G7 countries and the Euro area (aggregate) from 1973 delivers evidence that breaks occur not only in the level of (mean) inflation, but also in its seasonal pattern, dynamics (with the single exception of Canada) and volatility. These results contribute to the on-going debate (see, for example, Cecchetti and Debelle, 2006) about the nature of changes over time in the inflation process of developed economies. More specifically, we find that inflation persistence in virtually all countries considered (the only exception being Italy) is effectively zero in the latter part of the sample period, in line with a similar conclusion of Benati (2008), while inflation volatility increases around 1999 for the US and some other countries.

While our focus is univariate inflation, the analysis of Blanchard and Simon (2001) suggests that the increased inflation volatility we uncover from the end of the last century may be indicative of increased output volatility from around that date. Consequently, and also in the light of evidence of impending recession in many countries, the "Great Moderation" 
may prove to have been a temporary phenomenon. Further, the results in this paper point to a communality of break dates across countries for the mean and volatility of inflation, which indicates that a multi-country analysis may shed further light on international inflation linkages and how these have changed over time.

\section{References}

Ahmed, S. Levin, A. and Wilson, B.A., 2004. Recent U.S. macroeconomic stability: good policies, good practices or good luck? Review of Economics and Statistics 86, 824-832.

Altissimo, F., Matha, T., Bilke, L., Mojon, B. and Levin, A. 2006. Sectoral and aggregate inflation dynamics in the euro area. Journal of the European Economic Association 4, 585593.

Andrews, D.W.K. 1991. Heteroskedasticity and autocorrelation consistent covariance matrix estimation, Econometrica 59, 817-858.

Andrews, D.W.K. 1993. Tests for parameter instability and structural change with unknown change point. Econometrica 61, 821-856.

Arellano, M. (2006). Comment on Has the inflation process changed? Economic Policy, Apr 2006. 312-353.

Bai, J.S. and Perron, P., 1998. Estimating and testing linear models with multiple structural changes. Econometrica 66, 47-78.

Bai, J.S. and Perron, P., 2003. Computation and analysis of multiple structural change models. Journal of Applied Econometrics 18, 1-22.

Bai, J.S. and Perron, P. 2006. Multiple structural change models: A simulation analysis, in Econometric Theory and Practice: Frontiers of Analysis and Applied Research, D. Corbea, S. Durlauf and B. E. Hansen (eds.), Cambridge: Cambridge University Press, pp. 212-237.

Benati, L. 2008. Investigating inflation persistence across monetary regimes, Quarterly Journal of Economics 123, 1105-1160.

Bilke, L. 2005. Break in the mean and persistence of inflation: A sectoral analysis of French CPI. European Central Bank working paper No. 463.

Blanchard, O. and Simon, J. 2001. The long and large decline in U.S. output volatility. Brookings Papers on Economic Activity, 135-164.

Canova, F. and Hansen, B.E. 1995. Are seasonal patterns constant over time: A test for seasonal stability. Journal of Business \& Economic Statistics 13, 237-252.

Cecchetti, S.G. and Debelle, G. 2006. Has the inflation process changed? Economic Policy, Apr 2006, 312-353 (with discussion).

Clarida, R, Galí, J. and Gertler, M. 2000. Monetary policy rules and macroeconomic stability: Evidence and some theory, Quarterly Journal of Economics 115, 147-180. 
Clark, T.E. 2006. Disaggregate evidence on the persistence of consumer price inflation. Journal of Applied Econometrics 21, 563-587.

Commission of the European Communities 2000. On harmonization of consumer price indices in the European Union. $\operatorname{COM}(2000), 742$ final, Brussels.

Franses, P.H. and Haldrup, N. 1994. The effects of additive outliers on tests for unit roots and cointegration. Journal of Business and Economic Statistics 12, 471-478.

Ghysels, E. and Osborn, D.R. 2001. The Econometric Analysis of Seasonal Time Series. Cambridge: Cambridge University Press.

Ghysels, E. and Perron, P. 1996. The effect of linear filters on dynamic time series with structural change. Journal of Econometrics 70, 67-97.

Hamid, S.A. and Dhakar, T.S. 2008. The behaviour of the US consumer price index 19132003: A study of seasonality in the monthly US CPI. Applied Economics 40, 1637-1650.

Hansen, B.E. 1992. Testing for parameter instability in linear models. Journal of Policy Modelling 14(4), 517-533.

Hansen, B.E. 2000. Testing for structural breaks in conditional models. Journal of Econometrics 97, 93-115.

Harvey, A.C. 1989. Forecasting, Structural Time Series Models and the Kalman Filter. Cambridge University Press: Cambridge.

Herrera, A.M. and Pesavento, E. 2005. The decline in US output volatility: Structural changes and inventory investment. Journal of Business \& Economic Statistics 23, 462-472.

Levin, A.T. and Piger, J.M., 2004, Is inflation persistence intrinsic in industrial economies?, ECB Working Paper No. 334..

Marques, C.R. 2004. Inflation persistence: Facts or artefacts? ECB Working Paper No. 371.

McConnell, M.M. and Perez Quiros, G. 2000. Output fluctuations in the United States: What has changed since the early 1980s? American Economic Review 90, 1464-1476.

O'Reilly, G. and Whelan, K. 2005. Has Euro-area inflation: persistence changed over time? Review of Economics and Statistics 87, 709-720.

Osborn, D.R. and Sensier M. 2008. UK inflation: persistence, seasonality and monetary policy series. Scottish Journal of Political Economy, forthcoming.

Paya, I., Duarte, A. and Holden, K. 2007. On the relationship between inflation persistence and temporal aggregation. Journal of Money, Credit and Banking 39, 1521-1532.

Pitarakis, J.-Y. 2004. Least squares estimation and tests of breaks in mean and variance under misspecification. Econometrics Journal 7, 32-54.

Qu, Z.J., and Perron, P. 2007. Estimating and testing structural changes in multivariate regressions. Econometrica 75, 459-502.

Sensier, M. and van Dijk, D., 2004. Testing for volatility changes in US macroeconomic time series. Review of Economics and Statistics 86, 833-839.

Stock, J.H. and Watson, M.W. 2003. Forecasting output and inflation: The role of asset prices. Journal of Economic Literature 41, 788-829.

Stock, J.H. and Watson, M.W. 2005. Understanding changes in international business cycle dynamics. Journal of the European Economic Association 3, 9681006 . 
Stock, J.H. and Watson, M.W. 2007. Why has US inflation become harder to forecast?. Journal of Money, Credit and Banking 39, 3-33.

van Dijk, D., Franses, P.H., and Lucas, A. 1999. Testting for ARCH in the presence of additive outliers. Journal of Applied Econometrics 14, 539-562,

White, H. 1980. A heteroskedasticity-consistent covariance matrix estimator and a direct test for hetereskodasticity. Econometrica 48, 817-838. 
Figure 1: Canada Inflation Decomposition

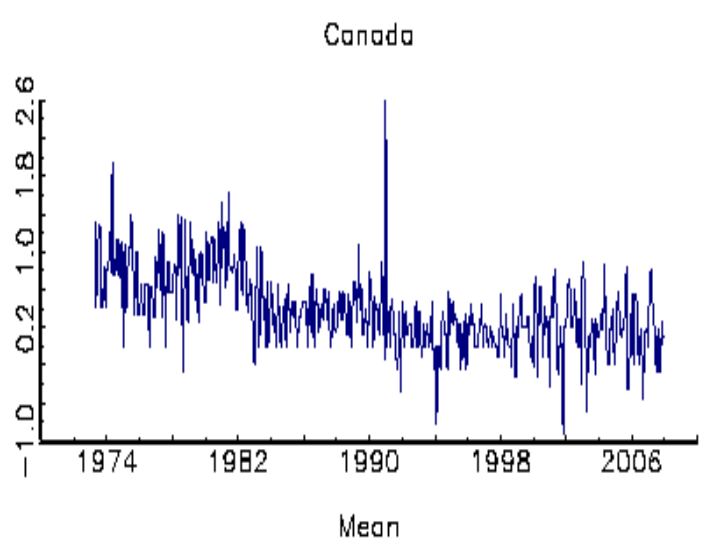

Dynamics, Persistence and Volatility
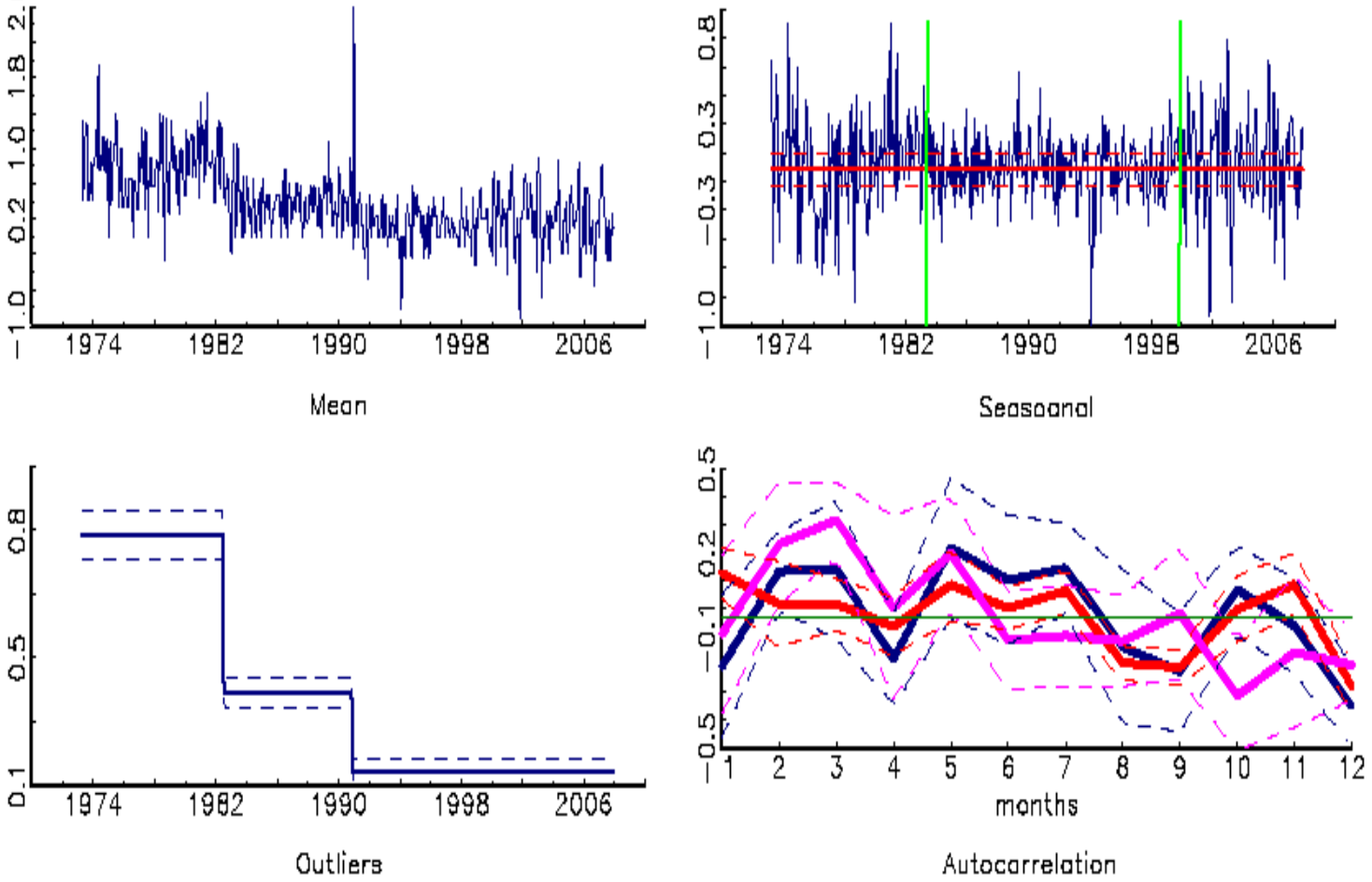

Autocarrelation
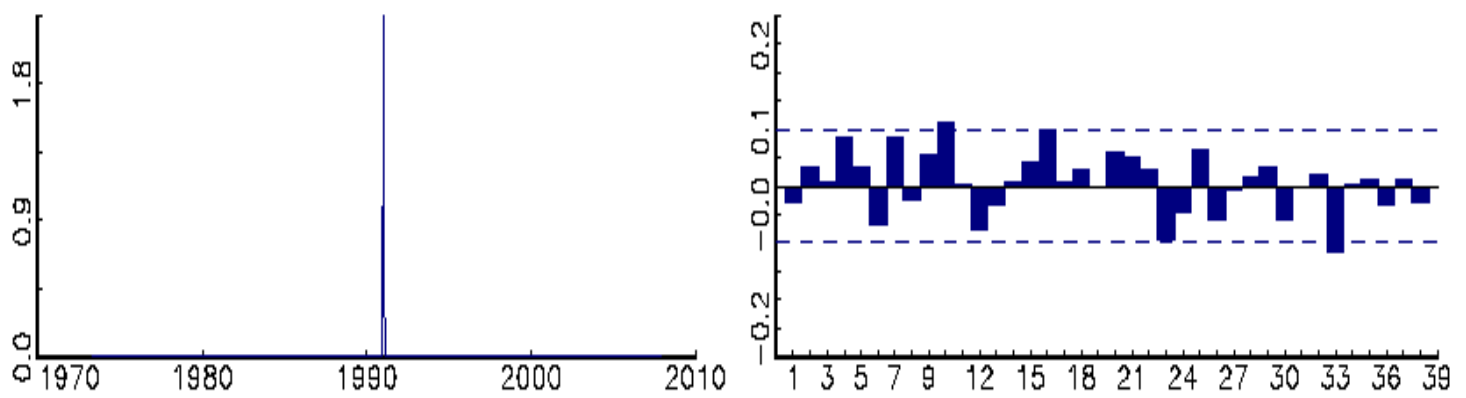

Notes: Panels (from left to right) show: (a) observed inflation, (b) dynamic component, persistence (red line) and volatility break dates (green vertical lines); (c) regime means, (d) deterministic seasonal component for regime 1 in blue, regime 2 in red and regime 3 in pink, (e) outliers and (f) correlogram for the estimated dynamic component over the sample period 1973.03 to 2007.12 . 95\% confidence intervals are shown as dashed lines. 
Figure 2: Euro Area Inflation Decomposition

Euro
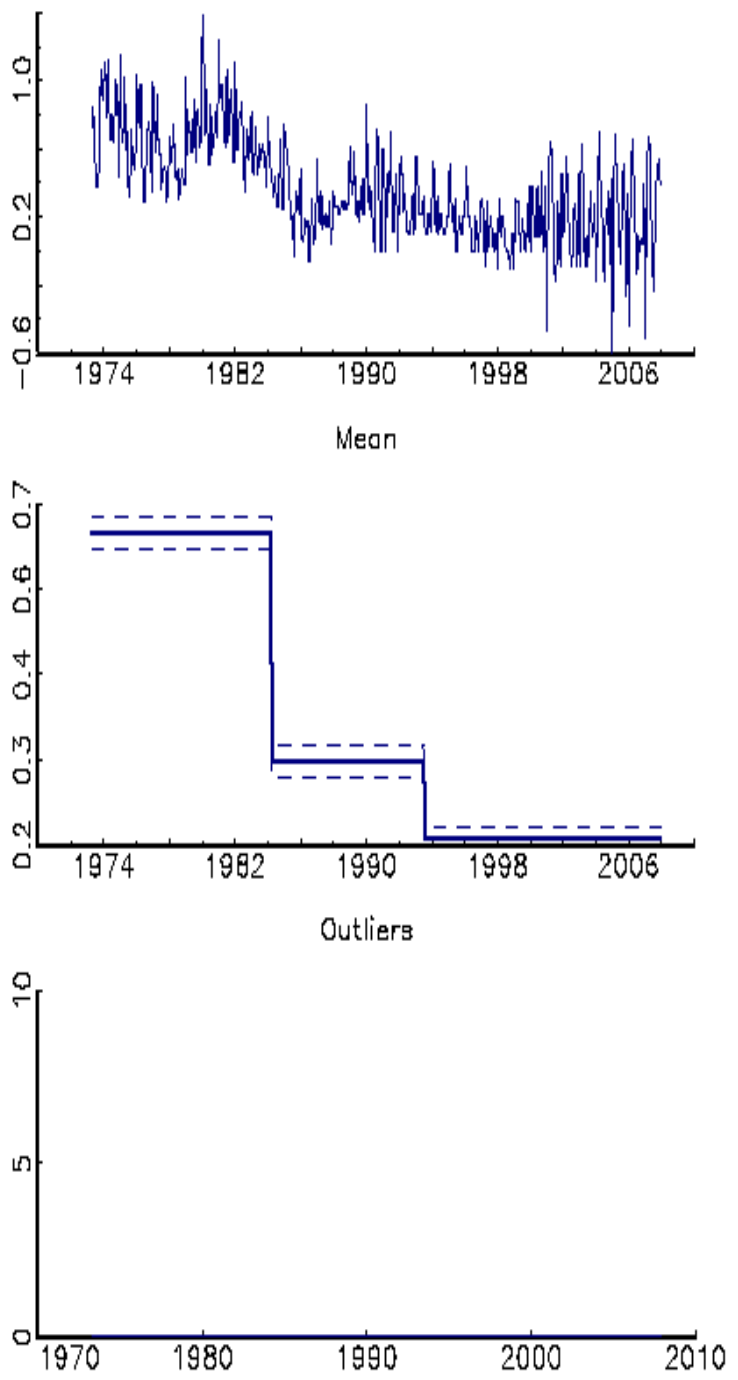

Dynamics, Pergistence and Volatility
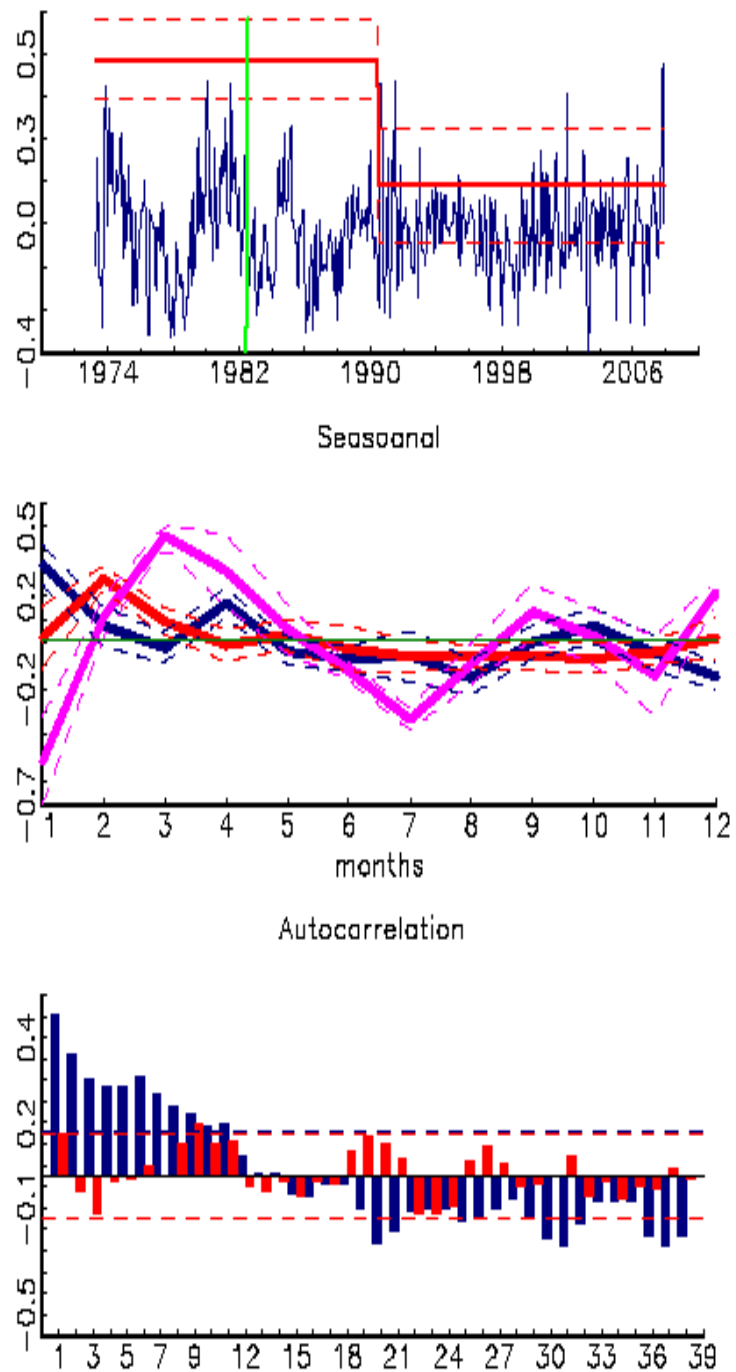

Notes: See Figure 1. 
Figure 3: France Inflation Decomposition
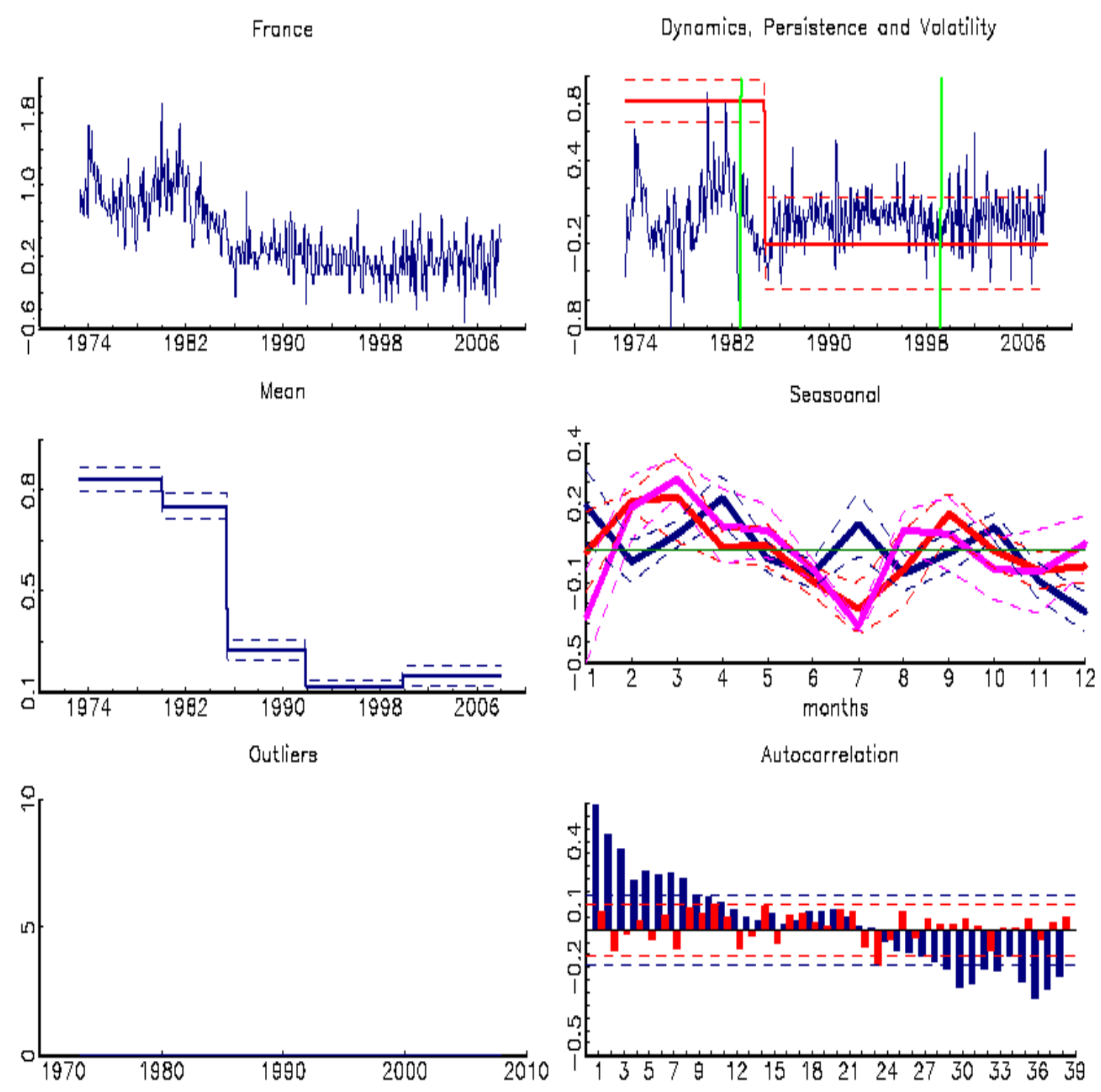

Notes: See Figure 1. 
Figure 4: Germany Inflation Decomposition
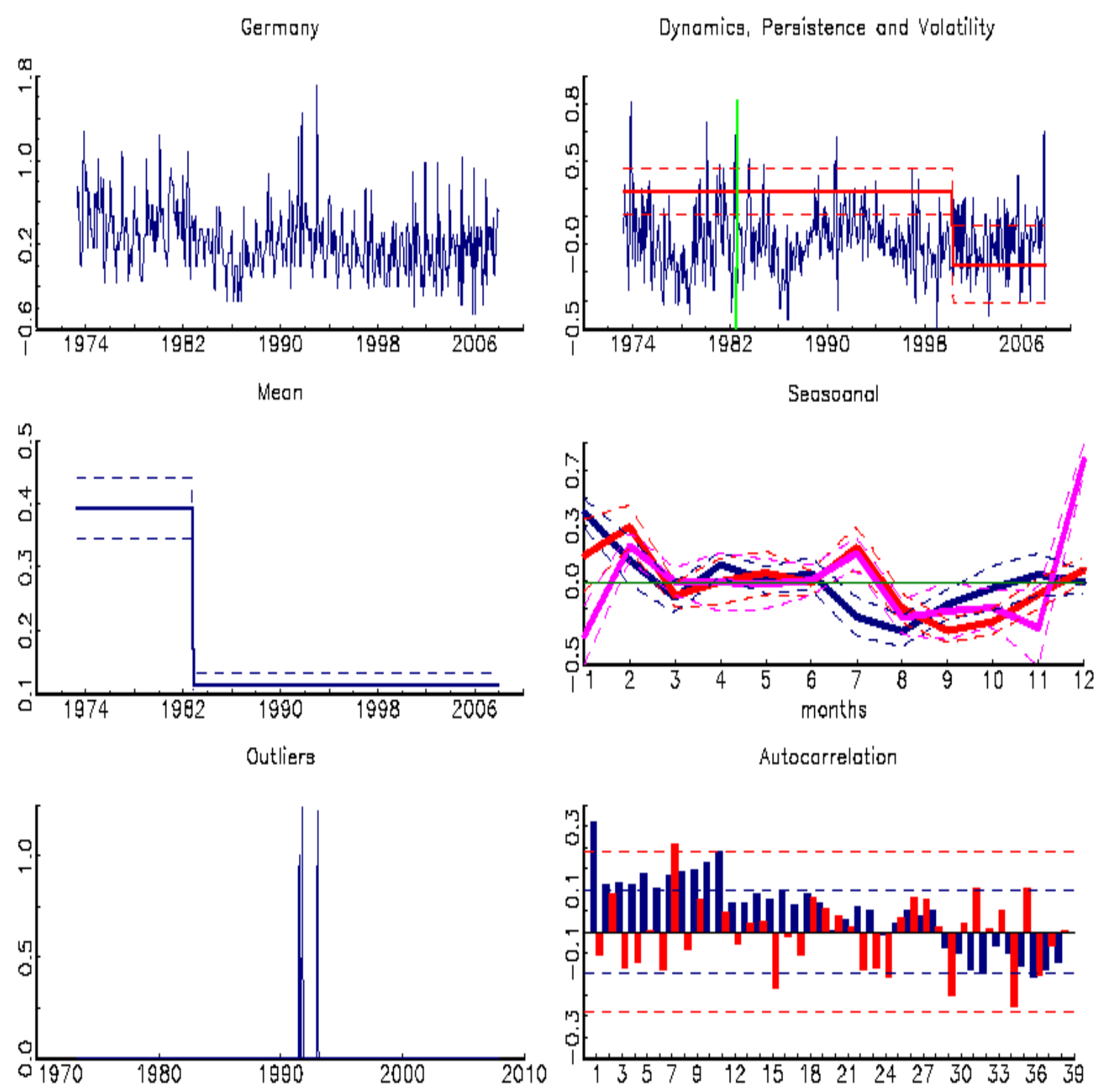

Notes: See Figure 1. 
Figure 5: Italy Inflation Decomposition

Itoly
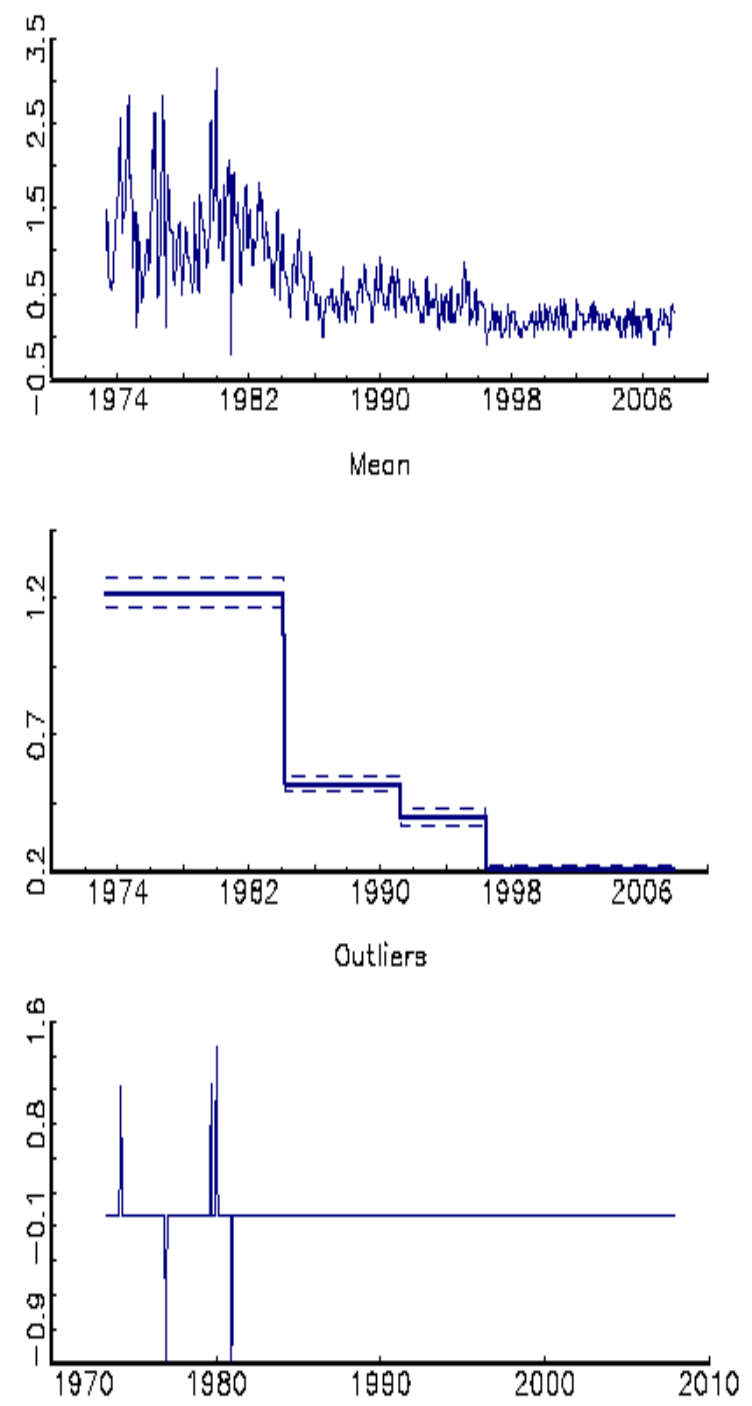

Dynamics, Persistence and Volatility
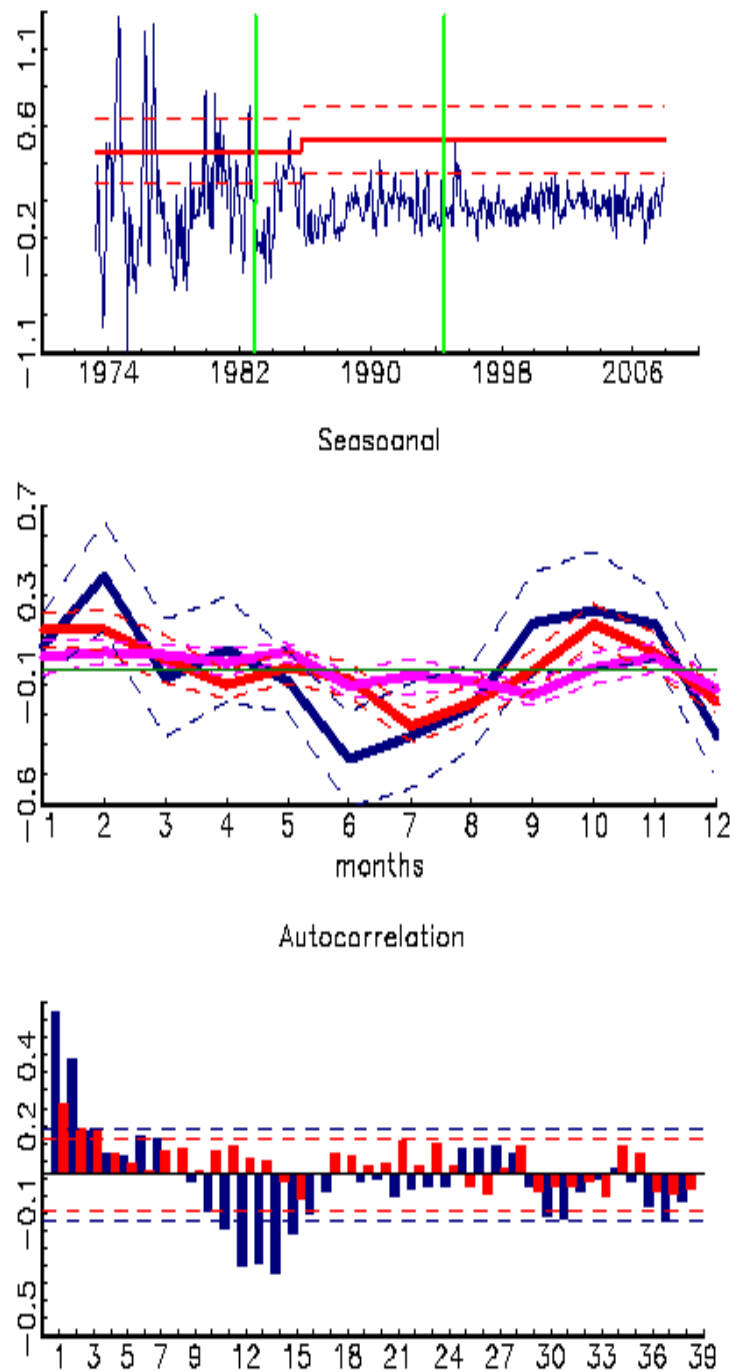

Notes: See Figure 1. 
Figure 6: Japan Inflation Decomposition

Japan

Dynamics, Pergistence and Volatility
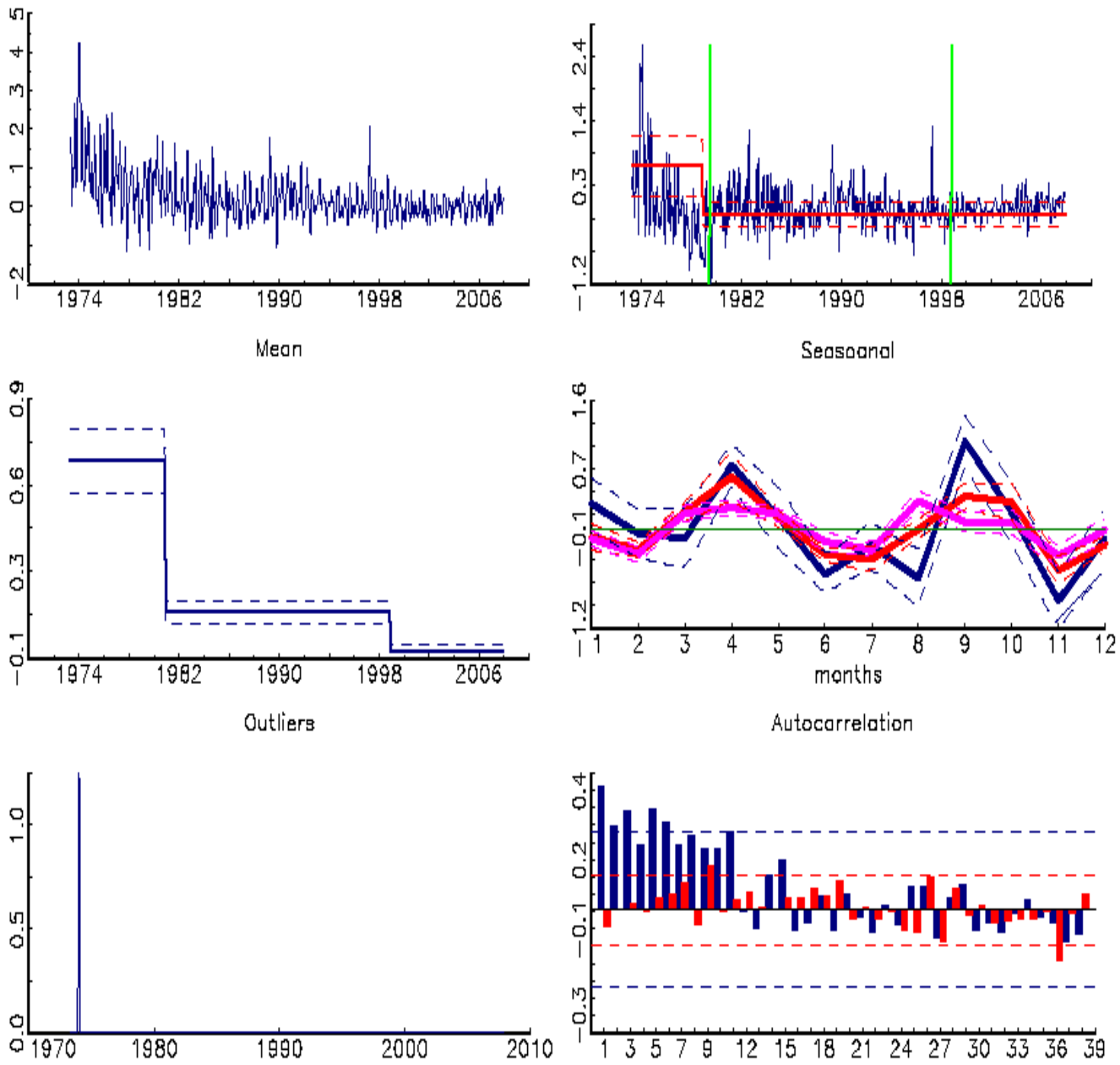

Notes: See Figure 1. 
Figure 7: UK Inflation Decomposition

UK
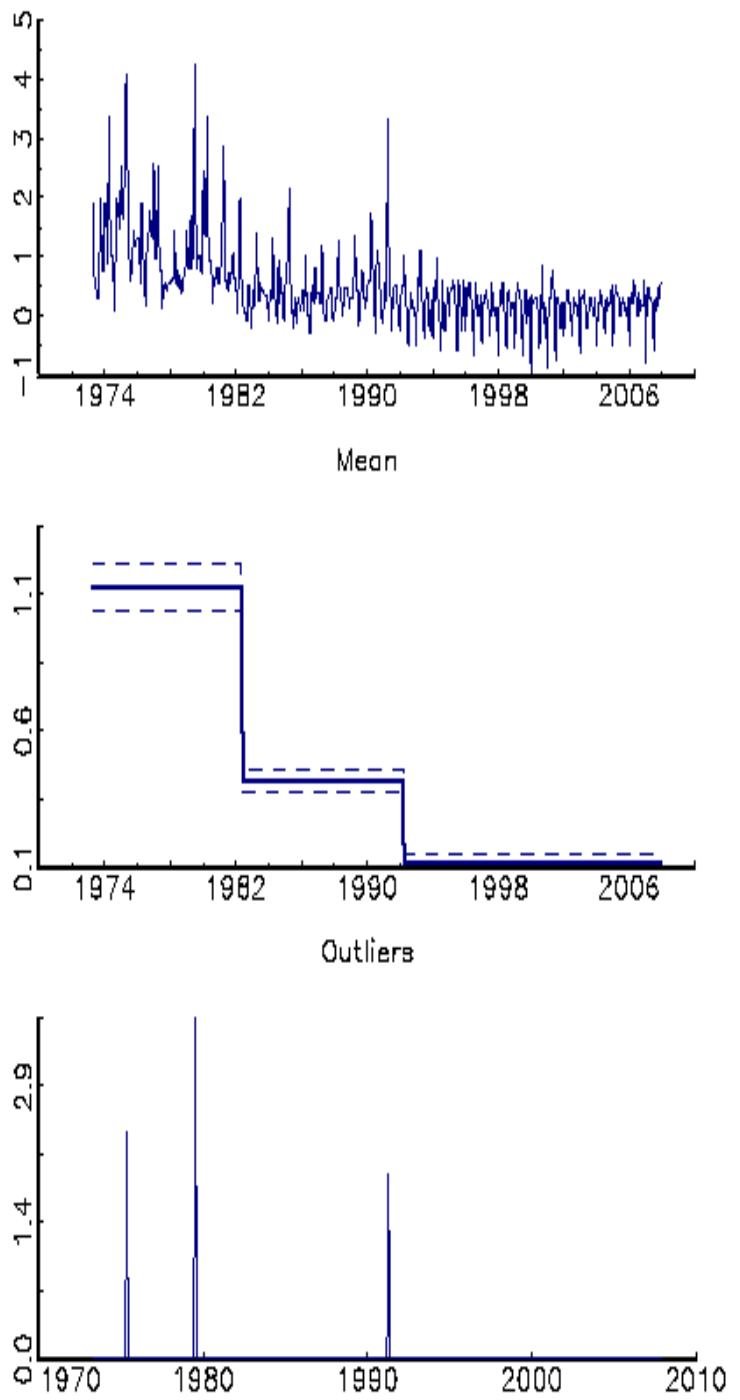

Dynamics, Persistence and Volatility
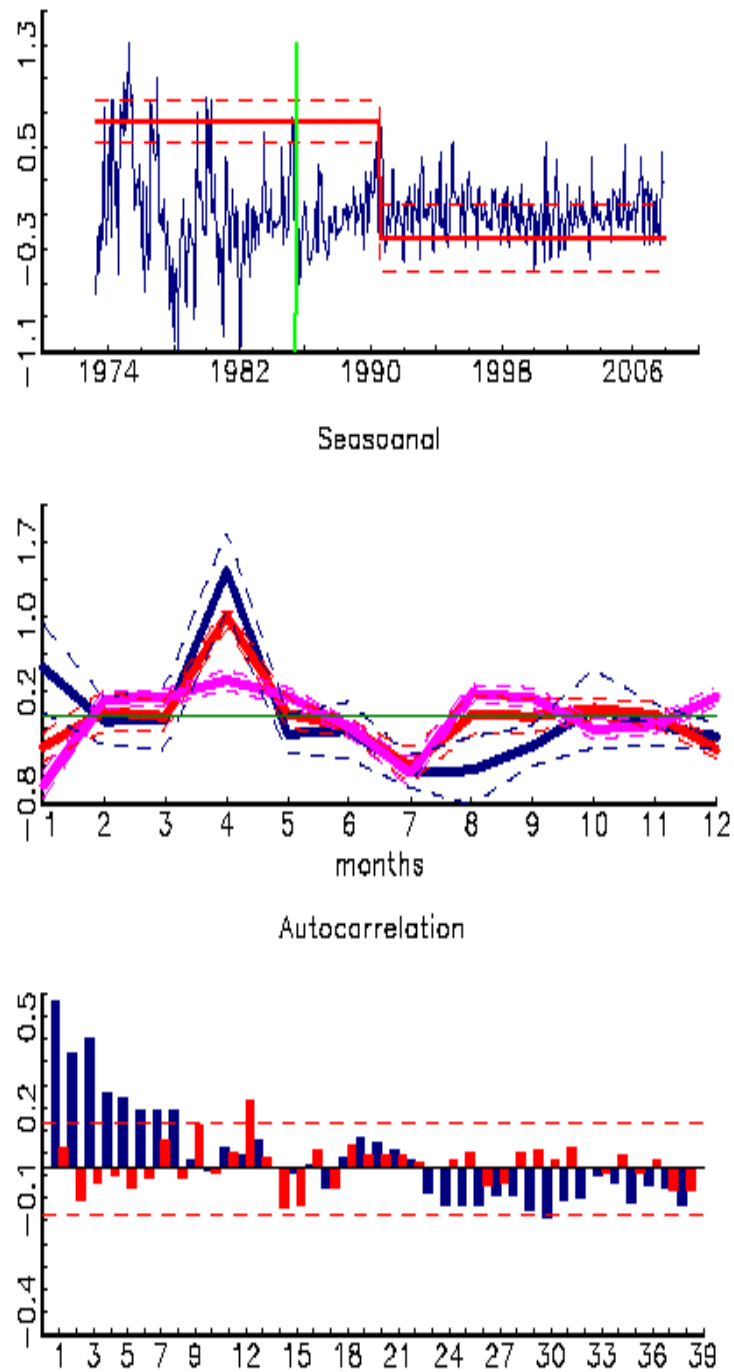

Notes: See Figure 1. 
Figure 8: US Inflation Decomposition

US
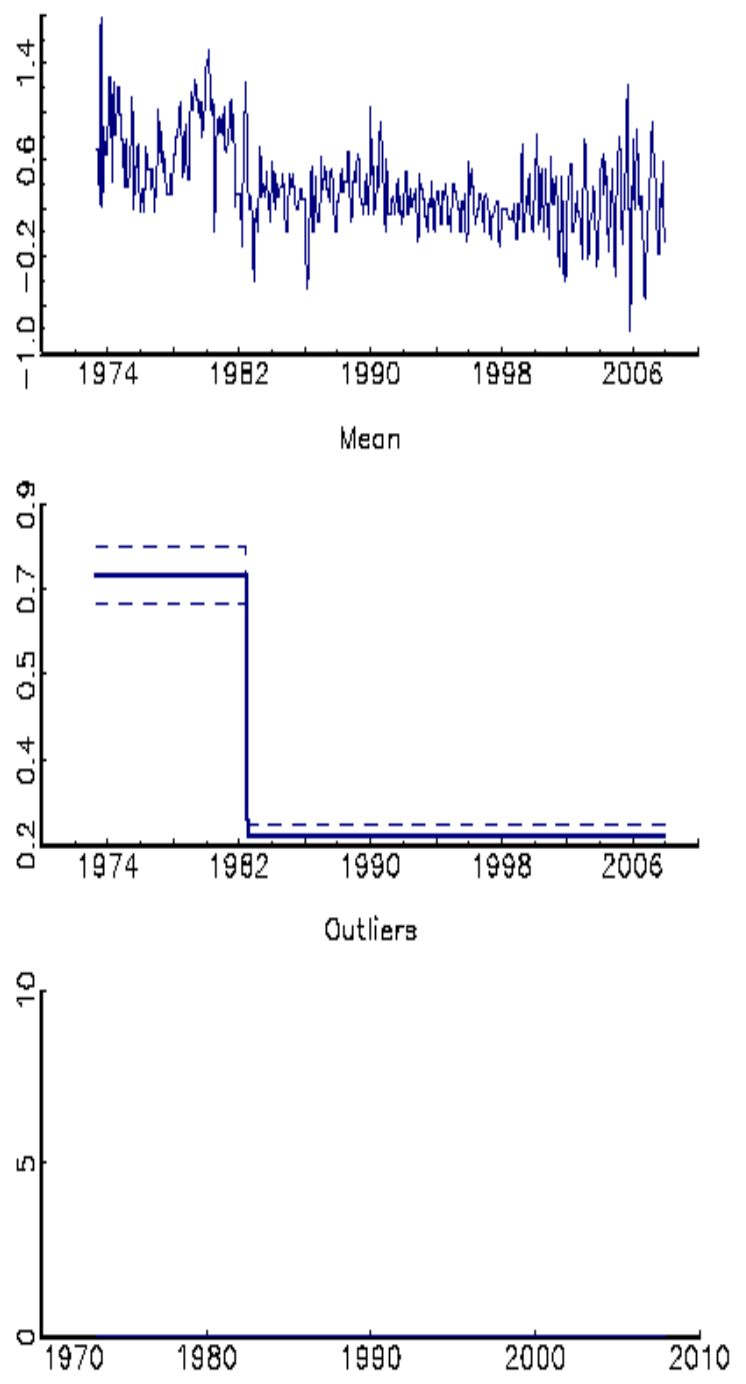

Dynamics, Persistence and Volatility
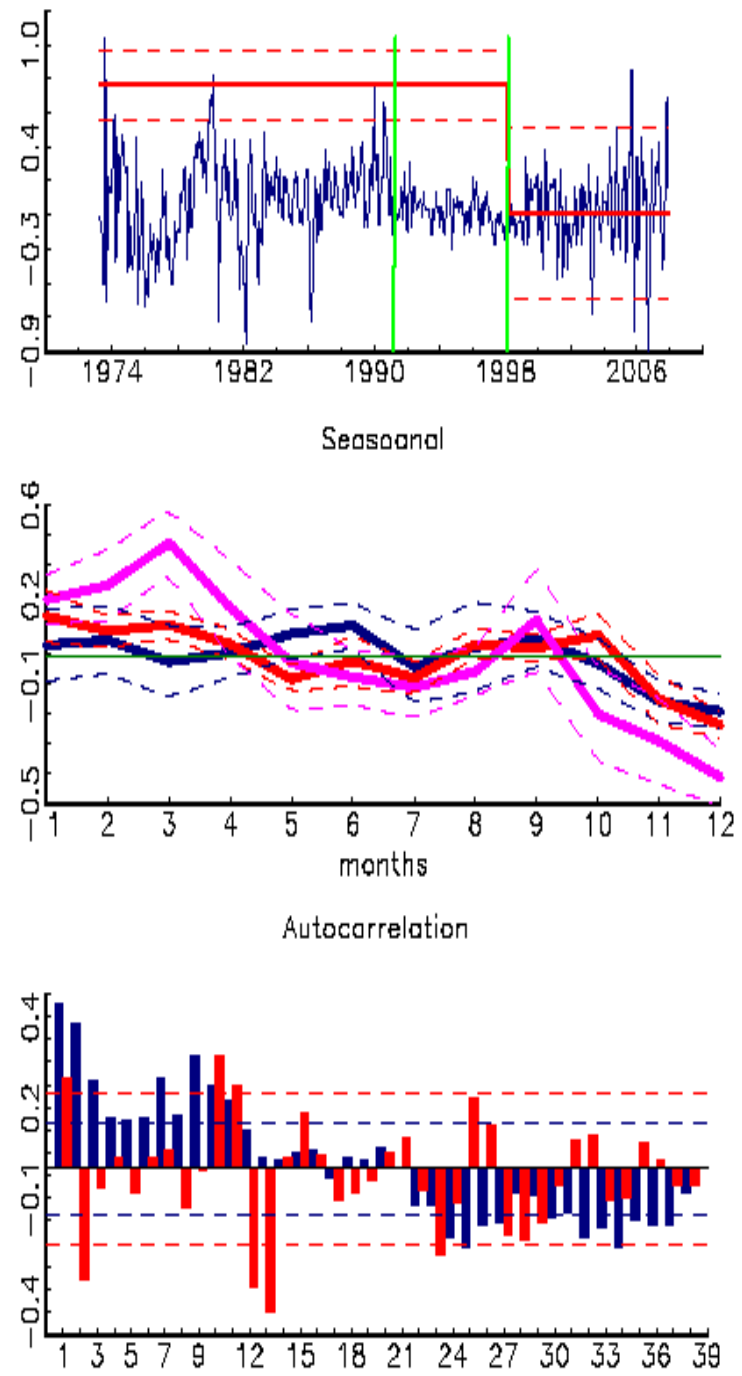

Notes: See Figure 1. 
Table 1. Structural breaks in mean, seasonality and outliers

\begin{tabular}{|c|c|c|c|c|c|c|c|}
\hline Canada & Euro Area & France & Germany & Italy & Japan & 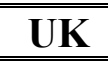 & US \\
\hline \multicolumn{8}{|c|}{ A. Mean breaks } \\
\hline 82.06 & & 80.01 & 82.10 & & 80.11 & 82.05 & 82.06 \\
\hline 82.02 & & 78.03 & 82.05 & & 80.07 & 82.03 & 82.04 \\
\hline \multirow[t]{4}{*}{82.10} & & 81.11 & 83.03 & & 81.03 & 82.07 & 82.08 \\
\hline & 84.03 & 85.05 & & 84.02 & & & \\
\hline & 84.01 & 85.04 & & 84.01 & & & \\
\hline & 84.05 & 85.06 & & 84.03 & & & \\
\hline 90.11 & 93.07 & 91.11 & & 91.03 & & 92.03 & \\
\hline 89.10 & 92.09 & 90.11 & & 89.06 & & 91.07 & \\
\hline \multirow[t]{4}{*}{91.12} & 94.05 & 92.11 & & 92.12 & & 92.11 & \\
\hline & & 99.11 & & 96.06 & 98.11 & & \\
\hline & & 88.12 & & 95.09 & 95.01 & & \\
\hline & & $07.12 *$ & & 97.03 & 02.09 & & \\
\hline \multicolumn{8}{|c|}{ B. Means across sub-sample (and ignoring mean breaks) } \\
\hline 0.79 & 0.67 & 0.88 & 0.41 & 1.25 & 0.71 & 1.08 & 0.73 \\
\hline 0.37 & 0.30 & 0.78 & 0.15 & 0.52 & 0.13 & 0.42 & 0.25 \\
\hline \multirow[t]{2}{*}{0.16} & 0.17 & 0.25 & & 0.39 & -0.03 & 0.15 & \\
\hline & & 0.12 & & 0.19 & & & \\
\hline$(0.38)$ & $(0.67)$ & $\begin{array}{c}0.16 \\
(0.88) \\
\end{array}$ & $(0.41)$ & $(1.25)$ & $(0.71)$ & $(1.08)$ & $(0.38)$ \\
\hline \multicolumn{8}{|c|}{ C. Seasonality breaks } \\
\hline 83.11 & & & & 83.12 & 84.09 & 81.09 & \\
\hline 80.11 & & & & 82.10 & 83.12 & 81.01 & \\
\hline \multirow[t]{4}{*}{86.11} & & & & 85.02 & 85.06 & 82.05 & \\
\hline & 91.12 & 92.01 & 92.01 & 95.07 & & 93.04 & 92.04 \\
\hline & 91.02 & 91.03 & 91.02 & 92.11 & & 92.08 & 88.11 \\
\hline & 92.10 & 92.11 & 92.12 & 98.03 & & 93.12 & 95.09 \\
\hline 99.07 & 00.08 & 98.12 & 00.01 & & 99.01 & & 99.03 \\
\hline 98.04 & 00.04 & 95.12 & 99.09 & & 96.10 & & 98.02 \\
\hline 00.10 & 00.12 & 01.12 & 00.05 & & 01.04 & & 00.04 \\
\hline \multicolumn{8}{|c|}{ D. S.D. of seasonal fluctuation across regimes (and ignoring seasonality breaks) } \\
\hline 0.23 & 0.41 & 0.34 & 0.40 & 0.35 & 0.51 & 0.61 & 0.14 \\
\hline 0.30 & 0.43 & 0.50 & 0.55 & 0.51 & 0.58 & 0.70 & 0.65 \\
\hline 0.26 & 0.75 & 0.47 & 0.47 & 0.31 & 0.65 & 0.75 & 0.59 \\
\hline$(0.26)$ & $(0.55)$ & $(0.40)$ & $(0.40)$ & $(0.38)$ & $(0.54)$ & $(0.67)$ & $(0.35)$ \\
\hline \multicolumn{8}{|c|}{ E. Outliers } \\
\hline \multirow[t]{5}{*}{91.01} & & & 91.07 & 74.03 & 73.12 & 75.05 & \\
\hline & & & 91.10 & 76.12 & 74.01 & 79.07 & \\
\hline & & & 93.01 & 79.09 & & 91.04 & \\
\hline & & & & 80.01 & & & \\
\hline & & & & 80.12 & & & \\
\hline \multicolumn{8}{|c|}{ F. AR orders } \\
\hline 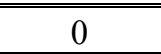 & 1 & 8 & 1 & 12 & 3 & 3 & 13 \\
\hline \multicolumn{8}{|c|}{ G. Number of iterations required for convergence in main-loop } \\
\hline 4 & 5 & 12 & $19^{*}$ & 6 & 5 & $19 *$ & 4 \\
\hline \multicolumn{8}{|c|}{ H. Model HQ criterion value } \\
\hline-7.41 & -7.4 & -10.03 & -6.08 & -10.37 & -6.39 & -5.01 & -10.53 \\
\hline
\end{tabular}

Notes: Decomposition of the components of (1) using the iterative method described in the text. Breaks are detected using the Qu and Perron (2007) structural break test (Mean: trimming 15\%, max breaks 5; Seasonal: trimming 20\% max breaks 2), with confidence intervals computed using HC standard errors. Panel A shows the estimated break dates 
for the level component in bold, together with lower and upper bounds of asymptotic $90 \%$ confidence intervals. Mean monthly inflation rates in the various subsamples determined by the level breaks are given in Panel B, with overall mean inflation estimated without levels breaks in parentheses. Panel $\mathrm{C}$ shows the estimated break dates for the seasonal component in bold, together lower and upper bounds of asymptotic $90 \%$ confidence intervals, with * indicating that the corresponding estimated bound lies outside the sample period (and is set to the final sample period). Panel D shows the standard deviation of the seasonal fluctuations in each subsample, that is $\left[\sum_{l=1}^{s} \hat{\delta}_{k_{2} l}^{2} /(s-1)\right]^{0.5}$, together with this measure computed ignoring seasonality breaks (in parentheses). The dates of detected outliers are given in Panel $\mathrm{E}$, where an outlier is defined as being 5 times the interquartile range from the median. Panel $\mathrm{F}$ indicates the autoregressive order of the dynamic component, selected according to the HQ information criterion, and used at entry to the dynamic/volatility sub-loop. Panel G shows the number of iterations of the main loop required to achieve convergence of the algorithm, with ** indicating that the iteration converged to a two cycle oscillation and choice between these is made based on HQ criterion. Finally, Panel H shows the value of the Hannan-Quinn criterion of the full model, defined in Equation (6) in the text. 
Table 2. Dynamic and volatility components of CPI decomposition

\begin{tabular}{|c|c|c|c|c|c|c|c|}
\hline Canada & Euro Area & France & Germany & Italy & Japan & UK & $\mathbf{U S}$ \\
\hline \multicolumn{8}{|c|}{ A. Dynamic breaks } \\
\hline & & & & & 79.02 & & \\
\hline & & & & & 76.10 & & \\
\hline & & & & & 81.06 & & \\
\hline & & 85.05 & & 86.10 & & & \\
\hline & & 84.08 & & 85.07 & & & \\
\hline & & 86.02 & & 88.01 & & & \\
\hline & 90.07 & & & & \multicolumn{3}{|c|}{90.10} \\
\hline & 87.01 & & & & \multicolumn{3}{|c|}{89.06} \\
\hline \multicolumn{8}{|c|}{92.02} \\
\hline & & & 00.05 & & & & 99.03 \\
\hline & & & 97.03 & & & & 98.01 \\
\hline \multicolumn{7}{|c|}{03.07} & 00.05 \\
\hline \multicolumn{8}{|c|}{ B. Persistence over sub-samples (and ignoring dynamic breaks) } \\
\hline \multirow[t]{2}{*}{-0.02} & 0.52 & 0.81 & 0.29 & 0.39 & 0.66 & 0.68 & 0.74 \\
\hline & 0.14 & -0.15 & -0.13 & 0.48 & -0.10 & 0.19 & -0.01 \\
\hline$(-0.02)$ & $(0.36)$ & $(0.67)$ & $(0.21)$ & $(0.40)$ & $(0.43)$ & $(0.59)$ & $(0.63)$ \\
\hline \multicolumn{8}{|c|}{ C. AR orders over sub-samples } \\
\hline \multirow[t]{2}{*}{0} & 1 & 1 & 1 & 1 & 3 & 3 & 3 \\
\hline & 0 & 0 & 0 & 1 & 0 & 0 & 2 \\
\hline \multicolumn{8}{|c|}{ D. Volatility breaks } \\
\hline & & & & & 79.09 & & \\
\hline & & & & & 75.11 & & \\
\hline & & & & & 79.11 & & \\
\hline 83.06 & 82.07 & 83.05 & 82.08 & 83.12 & & 85.09 & \\
\hline 75.01 & $73.03 *$ & 74.04 & 73.10 & 82.02 & & 82.09 & \\
\hline \multirow[t]{4}{*}{83.10} & 85.04 & 84.10 & 84.03 & 84.01 & & 85.11 & \\
\hline & & & & & & & 92.04 \\
\hline & & & & & & & 90.07 \\
\hline & & & & & & & 92.05 \\
\hline 99.12 & & 99.11 & & 95.06 & 99.01 & & 99.03 \\
\hline 99.06 & & 97.12 & & 90.11 & 96.10 & & 99.02 \\
\hline $07.12 *$ & & $07.12 *$ & & 97.07 & 99.05 & & 01.02 \\
\hline \multicolumn{8}{|c|}{ E. S.D. of shocks over sub-samples (and ignoring volatility breaks) } \\
\hline 0.33 & 0.16 & 0.20 & 0.24 & 0.32 & 0.64 & 0.37 & 0.22 \\
\hline 0.20 & 0.13 & 0.14 & 0.17 & 0.13 & 0.32 & 0.18 & 0.09 \\
\hline 0.32 & & 0.18 & & 0.10 & 0.16 & & 0.20 \\
\hline$(0.27)$ & $(0.14)$ & $(0.17)$ & $(0.19)$ & $(0.20)$ & $(0.37)$ & $(0.26)$ & $(0.19)$ \\
\hline \multicolumn{8}{|c|}{ F. Number of iterations required to converge in sub-loop } \\
\hline 2 & 3 & 3 & 3 & 3 & 3 & 3 & 3 \\
\hline
\end{tabular}

Notes: Decomposition of the breaks in AR process of (4) into dynamic and volatility components using the iterative method described in the text. Breaks are detected using the Qu and Perron (2007) structural break test with 15\% trimming and a maximum of 5 breaks, with confidence intervals computed as in Qu and Perron (2007) with homoscedastic errors. Panel A reports the estimated break dates in AR coefficients (in Bold) with asymptotic 90\% confidence intervals immediately below. Panel B reports estimated persistence, defined as the sum of autoregressive coefficients, based on sub-samples defined by the break dates (and, in parentheses, with no dynamic breaks). The AR orders chosen by HQ in each subsample are in Panel C. Panel D shows the estimated volatility breaks (in Bold) and their asymptotic $90 \%$ confidence intervals, with * indicating that the interval extends beyond the beginning/end of the sample period, with the reported date being the appropriate sample end-point.. Panel E has estimated standard deviations of the errors, in subsamples defined by the volatility break dates (and, in parentheses, with no volatility break). Panel F shows the number of iterations required for convergence of persistence and volatility breaks. 
Table 3. Sensitivity analysis

\begin{tabular}{|c|c|c|c|c|c|c|c|c|}
\hline & Canada & Euro Area & France & Germany & Italy & Japan & UK & $\mathbf{U S}$ \\
\hline \multicolumn{9}{|c|}{ A. Linear X-11 seasonal adjustment filter } \\
\hline $\begin{array}{l}\text { Mean breaks } \\
\text { (Dates) }\end{array}$ & $\begin{array}{c}2 \\
(83.03,91.01)\end{array}$ & $\begin{array}{c}2 \\
(84.02,93.07)\end{array}$ & $\begin{array}{c}2 \\
(84.10,91.11)\end{array}$ & $\begin{array}{c}1 \\
(82.10)\end{array}$ & $\begin{array}{c}3 \\
(80.01,85.06 \\
96.06)\end{array}$ & $\begin{array}{c}2 \\
(81.01,98.11)\end{array}$ & $\begin{array}{c}2 \\
(81.12,91.11)\end{array}$ & $\begin{array}{c}1 \\
(82.07)\end{array}$ \\
\hline Outliers & 1 & 0 & 0 & 0 & 5 & 3 & 3 & 0 \\
\hline $\begin{array}{l}\text { Dynamic breaks } \\
\text { (Dates) }\end{array}$ & 0 & $\begin{array}{c}1 \\
(88.08)\end{array}$ & $\begin{array}{c}1 \\
(86.02)\end{array}$ & 0 & $\begin{array}{c}1 \\
(80.07)\end{array}$ & 0 & $\begin{array}{c}1 \\
(90.10)\end{array}$ & $\begin{array}{c}2 \\
(84.04,91.07)\end{array}$ \\
\hline $\begin{array}{l}\text { Volatility breaks } \\
\text { (Dates) }\end{array}$ & $\begin{array}{c}2 \\
(84.05,99.12)\end{array}$ & $\begin{array}{c}1 \\
(00.03)\end{array}$ & $\begin{array}{c}1 \\
(82.11)\end{array}$ & $\begin{array}{c}3 \\
(83.08,88.10 \\
93.11)\end{array}$ & $\begin{array}{c}2 \\
(84.11,95.10)\end{array}$ & $\begin{array}{c}2 \\
(86.03,99.01)\end{array}$ & $\begin{array}{c}1 \\
(85.07)\end{array}$ & $\begin{array}{c}3 \\
(83.04,92.02, \\
01.06)\end{array}$ \\
\hline \multicolumn{9}{|c|}{ B. Deterministic components with no iterations } \\
\hline $\begin{array}{l}\text { Mean breaks } \\
\text { (Dates) }\end{array}$ & $\begin{array}{c}2 \\
(83.06,90.09)\end{array}$ & $\begin{array}{c}2 \\
(83.12,93.03)\end{array}$ & $\begin{array}{c}4 \\
(79.05,84.08, \\
91.11,99.11) \\
\end{array}$ & $\begin{array}{c}1 \\
(82.10)\end{array}$ & $\begin{array}{c}3 \\
(84.02,91.03 \\
96.06) \\
\end{array}$ & $\begin{array}{c}2 \\
(80.11,97.06)\end{array}$ & $\begin{array}{c}2 \\
(82.04,92.03)\end{array}$ & $\begin{array}{c}1 \\
(82.07)\end{array}$ \\
\hline $\begin{array}{l}\text { Seasonality breaks } \\
\text { (Dates) }\end{array}$ & 0 & $\begin{array}{c}2 \\
(85.04,00.08)\end{array}$ & 0 & $\begin{array}{c}2 \\
(93.04,00.08) \\
\end{array}$ & 0 & $\begin{array}{c}2 \\
(81.01,99.01)\end{array}$ & $\begin{array}{c}2 \\
(82.04,93.04) \\
\end{array}$ & 0 \\
\hline Outliers & 0 & 0 & 0 & 0 & 0 & 1 & 5 & 0 \\
\hline $\begin{array}{l}\text { Dynamic breaks } \\
\text { (Dates) }\end{array}$ & 0 & $\begin{array}{c}2 \\
(86.08,02.11) \\
\end{array}$ & $\begin{array}{c}1 \\
(87.01) \\
\end{array}$ & 0 & 0 & 0 & 0 & $\begin{array}{c}1 \\
(99.03) \\
\end{array}$ \\
\hline $\begin{array}{l}\text { Volatility breaks } \\
\text { (Dates) }\end{array}$ & $\begin{array}{c}5 \\
(78.10,84.06,89.09 \\
94.11,00.01) \\
\end{array}$ & 0 & $\begin{array}{c}1 \\
(83.05)\end{array}$ & $\begin{array}{c}5 \\
(78.08,83.10, \\
88.12,94.02,00.04) \\
\end{array}$ & $\begin{array}{c}3 \\
(81.01,86.04 \\
02.10) \\
\end{array}$ & $\begin{array}{c}2 \\
(79.08,97.04)\end{array}$ & $\begin{array}{c}2 \\
(82.02,91.05)\end{array}$ & $\begin{array}{c}3 \\
(83.04,92.04, \\
99.03) \\
\end{array}$ \\
\hline \multicolumn{9}{|c|}{ C. . Model for volatility breaks and outliers with no iterations } \\
\hline Outliers & 0 & 0 & 0 & 0 & 0 & 1 & 6 & 0 \\
\hline $\begin{array}{l}\text { Volatility breaks } \\
\text { (Dates) }\end{array}$ & $\begin{array}{c}5 \\
(79.02,84.06,89.10 \\
94.11,99.12)\end{array}$ & $\begin{array}{c}2 \\
(92.07,99.06)\end{array}$ & $\begin{array}{c}2 \\
(83.04,99.11)\end{array}$ & $\begin{array}{c}3 \\
(88.01,93.02 \\
00.03)\end{array}$ & $\begin{array}{c}1 \\
(82.08)\end{array}$ & $\begin{array}{c}1 \\
(84.09)\end{array}$ & $\begin{array}{c}2 \\
(81.06,91.06)\end{array}$ & $\begin{array}{c}3 \\
(83.04,92.04, \\
99.03)\end{array}$ \\
\hline \multicolumn{9}{|c|}{ D. Model for volatility breaks and outliers with iterations } \\
\hline Outliers & 1 & 0 & 0 & 0 & 5 & 3 & 5 & 1 \\
\hline $\begin{array}{l}\text { Volatility breaks } \\
\text { (Dates) }\end{array}$ & $\begin{array}{c}2 \\
(84.06,99.10)\end{array}$ & $\begin{array}{c}2 \\
(92.07,99.06)\end{array}$ & $\begin{array}{c}2 \\
(83.04,99.11)\end{array}$ & $\begin{array}{c}3 \\
(88.01,93.02 \\
00.03)\end{array}$ & $\begin{array}{c}3 \\
(80.11,86.04, \\
02.10)\end{array}$ & $\begin{array}{c}1 \\
(84.09)\end{array}$ & $\begin{array}{c}1 \\
(82.02)\end{array}$ & $\begin{array}{c}3 \\
(83.04,92.04, \\
99.03)\end{array}$ \\
\hline
\end{tabular}




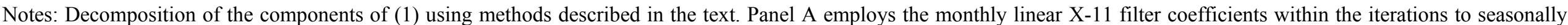

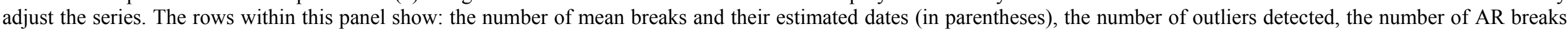

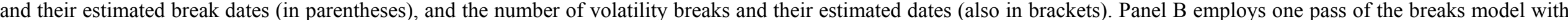

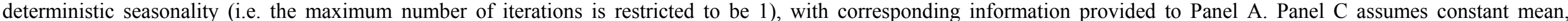

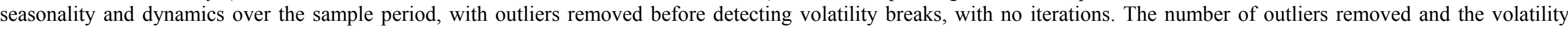

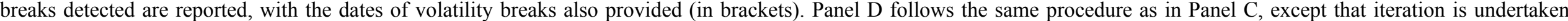
between outliers and volatility breaks, with a maximum of 20 iterations. In all cases, an outlier is defined as being 5 times the interquartile range from the median 